\title{
An investigation of breakage behaviour of single sand particles using a high-speed microscope camera
}

\author{
W. WANG* and M. R. COOP $\dagger$
}

\begin{abstract}
Much research has focused on the micro-mechanics of sand particles. The single particle uniaxial compression test is a common way to study breakage behaviour. However, there is still little agreement on particle breakage criteria and the mechanisms of breakage remain uncertain, partly because of the often rapid brittle failure of sand particles. In this study, a series of single particle uniaxial compression tests on different kinds of sand particles were carried out, using a high-speed microscope camera to capture the processes of breakage. This enabled a maximum of 2000 frames to be obtained per second to identify clearly the failure processes and crack propagation. Four failure modes have been proposed based on the rapidity of failure and the size and number of particle fragments created during the breakage: splitting, explosive, explosive-splitting and chipping. The relationship between the particle strength and the breakage mode has then been explored, investigating also whether immersion would affect the breakage mode and strength. The morphologies of the sand particles including local roundness, particle size, aspect ratio, regularity and two-dimensional sphericity were measured to investigate their influence. With assistance of the high-speed microscope camera, the crack initiation locations were identified and the frequency of different locations obtained, comparing the results with existing particle micro-mechanical theories.
\end{abstract}

KEYWORDS: laboratory tests; particle crushing/crushability; particle-scale behaviour; sands

\section{INTRODUCTION}

Over recent decades, a great number of studies of the macroscopic behaviour of sand have been carried out by means of 'single element' laboratory tests such as oedometer and triaxial tests (e.g. Been \& Jefferies, 1985; Hardin, 1985; Bolton, 1986; Coop \& Lee, 1993; Verdugo \& Ishihara, 1996; Bobei et al., 2009). The role of single particle failure in the mechanical properties and deformation characteristics of granular materials has been recognised and the single particle uniaxial compression test has been widely used in particlescale research. In this method a single particle is compressed diametrically between two polished rigid plates while the displacement and force on the particle are recorded. For example, McDowell \& Bolton (1998) studied the micromechanical behaviour of crushable materials and revealed that the aggregate yield stress was related to the tensile strength of the individual particle as determined by the tensile strength of the smallest grains. Nakata et al. (2001a) conducted a series of one-dimensional compression tests as well as single particle loading tests to investigate how the single particle characteristics relate to the macroscopic behaviour. The results showed that the particle size, initial void ratio, angularity, mineralogy and single particle tensile strength all affect the onedimensional compression behaviour of granular materials. Nakata et al. (2001b) then defined five stages of particle damage from microscope observations before and after oedometer tests to describe the extent of the crushing.

Manuscript received 9 November 2015; revised manuscript accepted 27 May 2016.

Discussion on this paper is welcomed by the editor.

* Department of Architecture and Civil Engineering, City University of Hong Kong, Hong Kong.

† University College London, London, UK; formerly City University of Hong Kong, Hong Kong.
According to Cavarretta \& O'Sullivan (2012), for a typical sand particle, there were five stages of behaviour under compression: initial rotation, asperities damage, elastic response, fragmentation and catastrophic crushing. Cavarretta et al. (2010) and Cavarretta \& O'Sullivan (2012) indicated that the initial contact displacement response for a single particle might be softer than expected from Hertzian theory, later stiffening, partly a result of the crushing of contact asperities and partly caused by particle rotation in the initial loading stages.

For crushable sands, the water content or the humidity can affect the particle strength significantly. Coop \& Lee (1995) found that in triaxial tests the particles of some sands in their dry condition were stronger than that in a saturated state. They attributed this to intra-particle suctions from small amounts of water remaining after conventional drying in particles that had intra-particle pores, such as decomposed granites or carbonate sands, whereas there was no effect in quartz sands that had no intra-particle porosity. Ovalle et al. (2015) indicated that even an increase of the ambient relative humidity can lead to weaker particles. In contrast to the mechanism of intra-particle suctions of Coop \& Lee (1995), they proposed, however, that the intrinsic mechanism behind it was that of stress corrosion, illustrated by Atkinson (1979) who suggested that crack propagation was governed by a chemical reaction between the siloxane bonds of the quartz particles and the environmental water. Michalkse \& Freiman (1982) also attributed the strength loss with time in a wet environment to the chemical interaction of water with the solid bonds at the crack tip. Based on this mechanism, Oldecop \& Alonso (2001, 2003) later proposed a conceptual model for rockfill compressibility in a wet condition. In addition to the corrosive effect of the water or water vapour, the adsorption of water and mineral dilution could change the surface energy and electrostatic effects around the crack tips that would affect the critical stress intensity factor.

Tsoungui et al. (1999) proposed a numerical model to investigate the stress field inside granular materials under 
compression, assuming the particle failed owing to internal tensile stresses. The stress regime in the grain was decomposed into a hydrostatic state and a deviatoric state. Russell \& Muir Wood (2009) analysed the stress field in an elastic sphere compressed by point loading while applying a multiaxial failure criterion which took the microstructural properties of grains into account. This indicated that the crack would initiate in the sphere where the ratio of the second or deviatoric stress invariant over the first or normal stress invariant reached a maximum.

Owing to the rapid brittle breakage of particles and, in some cases the complex internal structure of sand particles, the failure mechanisms are still not well known. Moreover, it is not clear if the several existing breakage mechanisms proposed for ideal particles actually correspond with those in natural sand grains. Zhao et al. (2015) performed single particle compression tests using X-ray micro-computed tomography (CT) to explore the particle fracture patterns of quartz sand and decomposed granite. The research concentrated on the characteristics of fragments after particle failure rather than the dynamic process of the breakage, because of the time-consuming process of CT scanning. They highlighted that in neither type of particle was there a vertical split at failure as might be expected from a simple tensile failure, as will be discussed in detail later, making comparisons with the new data from this study.

The present study aims at a better understanding of the microscopic behaviour of natural sands and the crack initiation as well as propagation under uniaxial compression. Although the view of the breakage process is limited to an external one, the investigation complements those done with CT scanning by using a high-speed microscope camera so that initiation and progression of failure can be monitored. A series of single particle uniaxial compression tests on two types of crushable sand, Leighton Buzzard sand (LBS) and completely decomposed granite (CDG), have been carried out in both dry and immersed conditions. The effect of the morphology on particle strength was also investigated.

\section{APPARATUS AND MATERIALS}

The system used is shown in Fig. 1, and consists of a high-speed camera fitted with a microscope lens, used in conjunction with a high-intensity focused lighting system to capture the failure mechanisms while conventional instrumentation, a load cell with a linear variable differential transducer (LVDT), are data logged. A normal microscope camera is located orthogonally to the direction of the highspeed camera view. The loading frame is stiff, to minimise stored energy.

The high-speed camera (labelled (1) in Fig. 1) allows a maximum of 2130 frames to be captured per second to 'freeze' the loading process. This is combined with a microscope lens (2), which has an adjustable magnification up to 16 times. The frame rate used in this study was 1000 frames/s rather than the maximum value, as a compromise is needed with the exposure rate. More frames shot per second would lead to lower and so poorer picture quality. A high-intensity focused lighting system (3) was necessary to maximise exposure and so allow the fastest rate possible. In addition, some image-processing software programs (ImageJ and Sony Vegas) were also used to improve the picture quality. The normal microscope camera (4) is used to obtain the morphology of the grains in the orthogonal orientation. For the normal microscope camera, however, the intensity of light is too strong and an adjustable polarising filter (5) is placed in front of the camera lens. The loading speed used in these tests was $0 \cdot 1 \mathrm{~mm} / \mathrm{min}$. According to Antonyuk et al. (2005), particle strength increases with the velocity of the

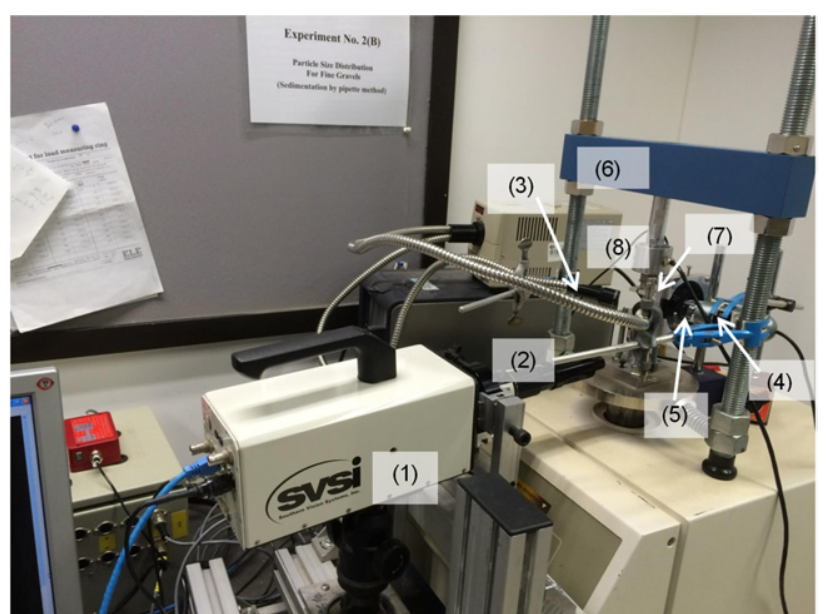

Fig. 1. The apparatus: (1) high-speed camera; (2) microscope lens; (3) high-intensity focused light; (4) normal microscope camera; (5) filters; (6) loading frame; (7) LVDT transducer; (8) upper load cell

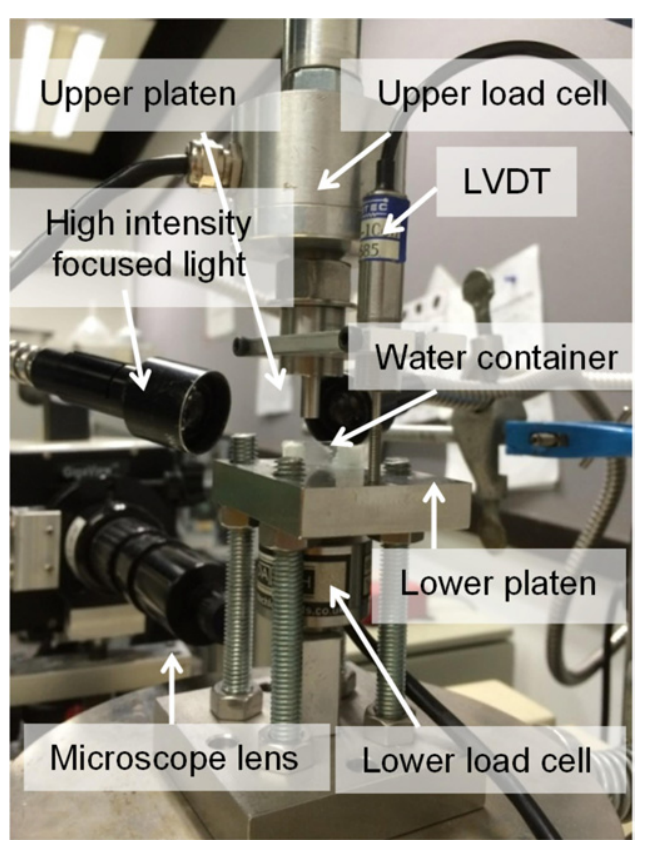

Fig. 2. Details of load cells and mounts

loading because less time is available for creep and consequent storage of elastic energy in the particle. The quite low loading velocity used in this study was determined by the feasibility of the observation of the particle damage. The camera permitted either continuous image acquisition or the retrospective capture of a short time period before a trigger was activated. Too slow a loading rate meant that very large amounts of computer memory were required for the videos, whereas too fast a rate made it difficult to capture all of the damage events.

The deformation along the loading axis was measured by an LVDT (6) with a precision of about $0 \cdot 2 \mu \mathrm{m}$, the LVDT being placed below the upper load cell (7) to avoid the load cell compliance affecting the accuracy (Fig. 2). Initially the measurement range of the load cell was too large to give accurate data at the start of some of the tests, the capacity being dictated by the strength of the strongest particle tested. Two load cells A (upper) and B (lower) with different capacities were therefore assembled in series. When the test started, both of the load cells recorded the force, but the 
value obtained from load cell $\mathrm{B}$ was adopted. Close to the capacity of load cell $\mathrm{B}$, it was protected by locking the nuts on the four stiff bolts around it, and the reading from load cell A was adopted thereafter. To improve further the system stiffness and the repeatability of displacement measurement, the upper loading platen attached to the upper load cell was made from a single piece of stainless steel and kept as short and broad as possible and the lower platen was simply a stainless steel plate, thereby avoiding unnecessary connections in the mounts that could give non-repeatable displacement components. Both the platens were polished to reduce friction between the mounts and particles. A glass water bath was located on the lower platen to enable the sand particles to be immersed (Fig. 3).

Two sands were tested, LBS and CDG, with sizes of $1.18 \sim 2.36 \mathrm{~mm}$ and $2 \cdot 36 \sim 5.00 \mathrm{~mm}$, for both sands. The former is a quartzitic sand from the UK, with visually sub-rounded, translucent and brown or white particles with a greasy lustre. The CDG particles, by contrast, are more opaque and irregular and composed mainly of quartz and feldspar, as discussed in more detail later.

From previous research (e.g. Hiramatsu \& Oka, 1966; Jaeger, 1967; Lee, 1992; Nakata et al., 1999, 2001a, 2001b), the single particle strength may be quantified by a maximum tensile stress $\sigma_{\mathrm{f}}$, and Cavarretta \& O'Sullivan (2012) proposed the following expression

$$
\sigma_{\mathrm{f}}=\frac{0 \cdot 225 N}{d^{2} / 4}=\frac{0 \cdot 9 N}{d^{2}}
$$

where $N$ is the force at particle failure and $d$ is the particle dimension, taken as $d=\left(d_{2} d_{3}\right)^{1 / 2}$, where $d_{2}$ and $d_{3}$ are the dimensions of the minimum section of the smallest circumscribable cuboid (SCC) of the particle, that is, the intermediate and minimum diameters. As the loading axis passes through the smallest dimension of irregular particles (Hiramatsu \& Oka, 1966), it is likely that the area of the vertical minimum section controls the resistance, in contrast to the simpler approach adopted by Nakata et al. (1999) of using $d=d_{3}$. The factor 0.9 falls in between $2 / \pi$ (Brazilian disc formula) and 1 (Lee, 1992) and is more appropriate to describe the stress state in three-dimensional particles.

In order to account for the variability of particle strength resulting from variability of size and number of initial flaws inside particles, McDowell \& Bolton (1998) proposed that the relationship between the survival probability of a particle and the tensile stress should be based on Weibull (1951) statistics

$$
P_{\mathrm{s}}=\exp \left[-\left(\frac{\sigma}{\sigma_{0}}\right)^{m}\right]
$$

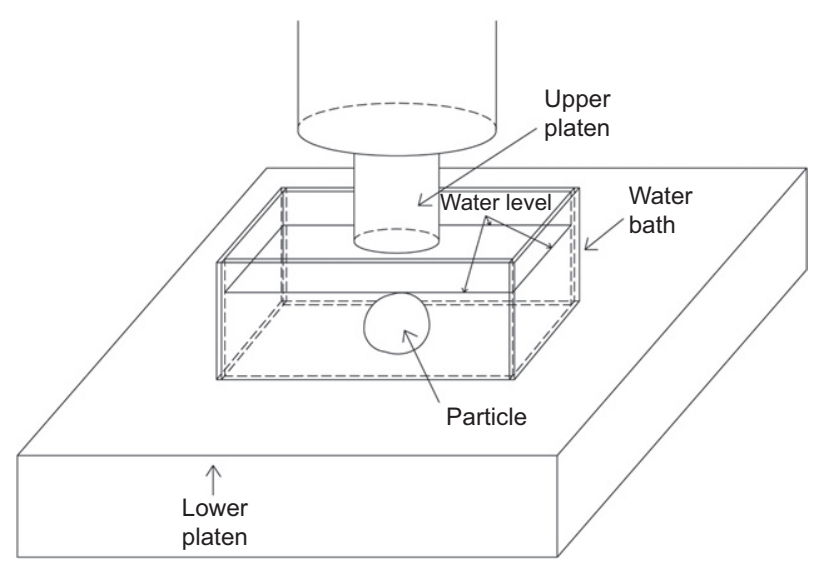

Fig. 3. Schematic diagram showing loading platens and water bath where $P_{\mathrm{s}}$ is the survival probability of a particle experiencing a tensile stress $\sigma, \sigma_{0}$ is the characteristic strength, defined so that the strength of $37 \%$ of the particles in a total volume is higher or equal to this value and $m$ is the Weibull modulus used to describe the uniformity of the strength, which is related to the variation of $\sigma$ within a given population of particles. An increasing of value of $m$ indicates a decreasing variability in particle strength.

\section{FAILURE MODES, TEST CONDITIONS AND PARTICLE STRENGTHS}

A summary of the total number of tests carried out for different materials, particle sizes and test conditions is given in Table 1. Using the high-speed microscope camera, the crushing process could be observed in most cases except for a few extremely rapid breakages. Based on the nature of the failure, the number of fragments and the intensity of failure, the breakages have been classified into four modes which are discussed in detail below. The results indicate that there were no obvious differences in failure mode between the different sand sizes and testing conditions (immersed or dry) for the same material.

\section{Splitting}

In the splitting mode the particle splits into two or three large pieces without the creation of numerous small fragments. The relationships between force and displacement for typical splitting mode tests for LBS and CDG particles are shown in Fig. 4. The numbers on the figure refer to images that have been taken from the high-speed microscope camera. The displacements have been corrected for apparatus compliance.

In the initial loading stages of the LBS particle, the response is slightly concave in shape. As the forces increase beyond a certain threshold (point 1 at about $6 \mathrm{~N}$ ), the curve

Table 1. Summary of the tests

\begin{tabular}{c|c|c|l|l}
\hline \multirow{2}{*}{} & \multicolumn{2}{|c|}{$1 \cdot 18 \sim 2 \cdot 36 \mathrm{~mm}$} & $2 \cdot 36 \sim 5.00 \mathrm{~mm}$ \\
\cline { 2 - 5 } & Immersed & Dry & Immersed & Dry \\
\hline $\begin{array}{c}\text { Leighton Buzzard sand } \\
\begin{array}{c}\text { Completely decomposed } \\
\text { granite }\end{array}\end{array}$ & 67 & 51 & Nil & 89 \\
\hline
\end{tabular}

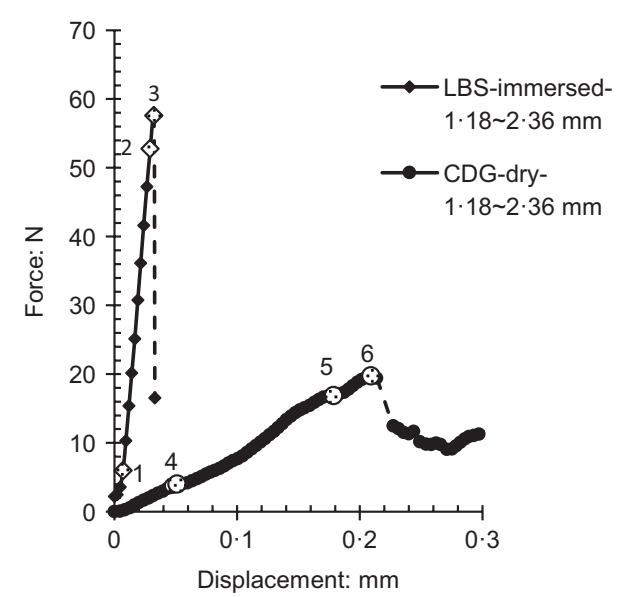

Fig. 4. Force-displacement curves of a typical splitting mode failure for a LBS particle $(1 \cdot 18 \sim 2 \cdot 36 \mathrm{~mm}$, immersed) and a CDG particle $(1 \cdot 18 \sim 2 \cdot 36 \mathrm{~mm}$, dry $)$ 
tends to be almost linear and then drops abruptly at failure, point 3 . The initially softer response was attributed to the damage of particle asperities by Cavarretta et al. (2010). The CDG particle is much softer and weaker than the LBS and the force drops to a lower value rather than to zero at failure, the particle seeming to continue to carry some residual load after breakage.

Corresponding to Fig. 4, the images of Figs 5 and 6 illustrate the particle crushing process in the splitting mode for LBS and CDG particles, respectively. In Fig. 5, there is no noticeable change in the particle from point 1 to point 2 . At point 3, the peak of the force-displacement curve, a crack occurs along the loading axis in the lower part of the particle. Almost immediately, the crack propagates from bottom to top, resulting in the particle splitting into two parts. Very few fragments are created by the process and the failure is quite mild in nature. After breakage, the two pieces fall to lie on the lower platen corresponding to the force reducing to zero. In contrast to the brittle behaviour with rapid initiation and propagation at the peak force for the LBS, for the softer $\mathrm{CDG}$, the main cracks develop more gradually. In frame 5 of Fig. 6, the top surface of the particle seems to be flattened and then the crack initiates from the top to the middle of the particle. In frame 6 of Fig. 6 , the fragments remain between the two platens with little movement after failure, giving a significant residual strength. In both cases the crack is propagating slightly before the peak stress, $\sigma_{\mathrm{p}}$, but this has little influence on the mechanical response immediately prior to failure.

\section{Explosive}

The second failure mode is explosive, defined as the particle undergoing a dramatic and instantaneous blasting into a mass of tiny fragments. Fig. 7 shows the force-displacement curves of a typical explosive mode for LBS (1.18 2.36 mm, immersed) and CDG $(1.18 \sim 2.36 \mathrm{~mm}$, dry) followed by corresponding camera images in Figs 8 and 9. For the LBS little of note happens for long durations after the loading has started until a shadow occurs below the middle of the particle, just before point 2 (Figs 7 and 8), which is close to the final failure. The shadow (frame 2, Fig. 8) implies a crack initiation, as in this case the particle is back-illuminated. Once the crack occurred, it propagated very quickly at point 3 (Fig. 8) causing a catastrophic breakage within $0.04 \mathrm{~s}$ with an audible noise. The explosive process is sudden and fierce so that the fragments fly too quickly even to be captured by the high-speed microscope camera and are out of focus in frames 3-1 and 3-2 (Fig. 8). For the mechanical behaviour in Fig. 7, the unloading response is represented by a dashed line indicating inaccurate measurement owing to the release of stored energy in the loading apparatus. For the CDG, after point 4 in Fig. 7, the force-displacement curve steepens, followed by a small saw tooth response immediately prior to a sudden failure at point 5. Like the LBS, the CDG particle broke into a very large number of fragments with high velocity (Fig. 8).

\section{Chipping}

Strictly speaking, chipping is not a final failure mode, as a minor part splits away from the particle during compression while the major part may remain between the two loading platens continuing to support substantial loads. However, the chipping may change the sectional area of the particle under load, often leading to particle movement and resulting in the force reducing. Fig. 10 gives typical force-displacement curves for the chipping mode for LBS and CDG. All the frames in Fig. 11 correspond to a very short time period

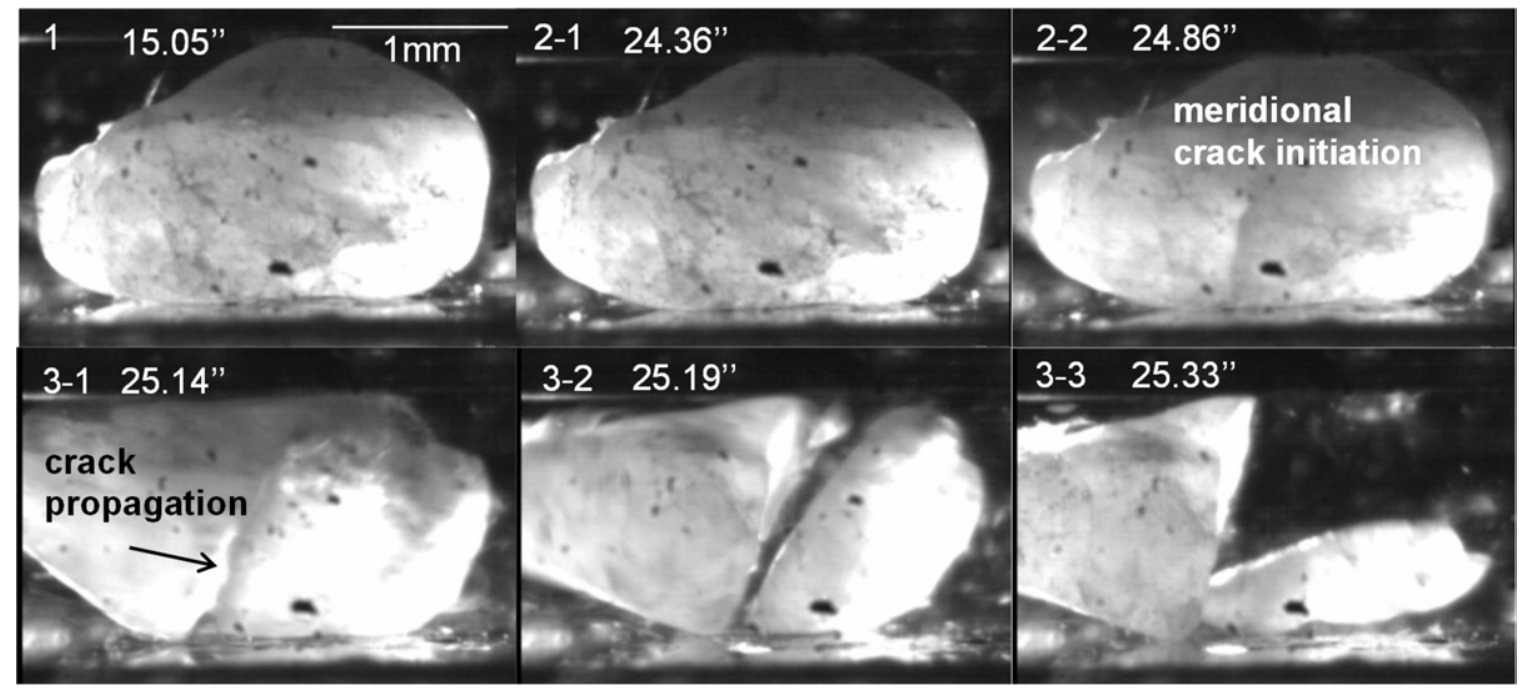

Fig. 5. A typical splitting mode failure for the LBS particle (1.18 $\sim 2.36 \mathrm{~mm}$, immersed) of Fig. 4

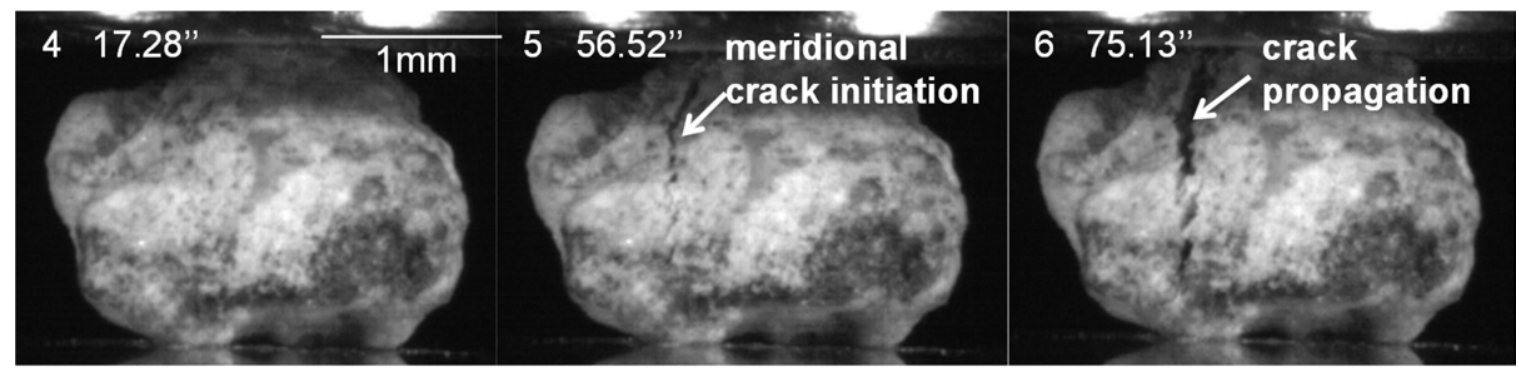

Fig. 6. A typical splitting mode failure for the CDG particle (1.18 $\sim 2.36 \mathrm{~mm}$, dry) of Fig. 4 
around the peak point 1 for the LBS. In frame $1-2$, it can be observed that a shadow occurred in the left upper part, which implies a crack initiation here. Within $0 \cdot 1 \mathrm{~s}$ the crack propagates from top to bottom and a minor part is chipped away from the main body. The force drops rapidly, but if the displacement were continued then the remaining part of the particle would eventually be loaded. For the CDG particle, before the failure, from point 2 to point 3 (Fig. 12), the shape of the particle did not change significantly and no obvious cracks were detected. At the moment of failure, two cracks occurred that were transverse and longitudinal.

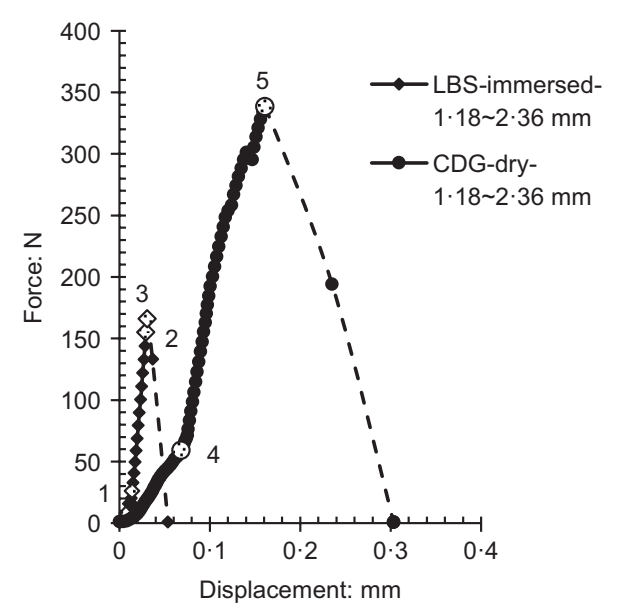

Fig. 7. Force-displacement curves of a typical explosive mode failure for a LBS particle $(1.18 \sim 2.36 \mathrm{~mm}$, immersed) and a CDG particle $(1 \cdot 18 \sim 2.36 \mathrm{~mm}$, dry)

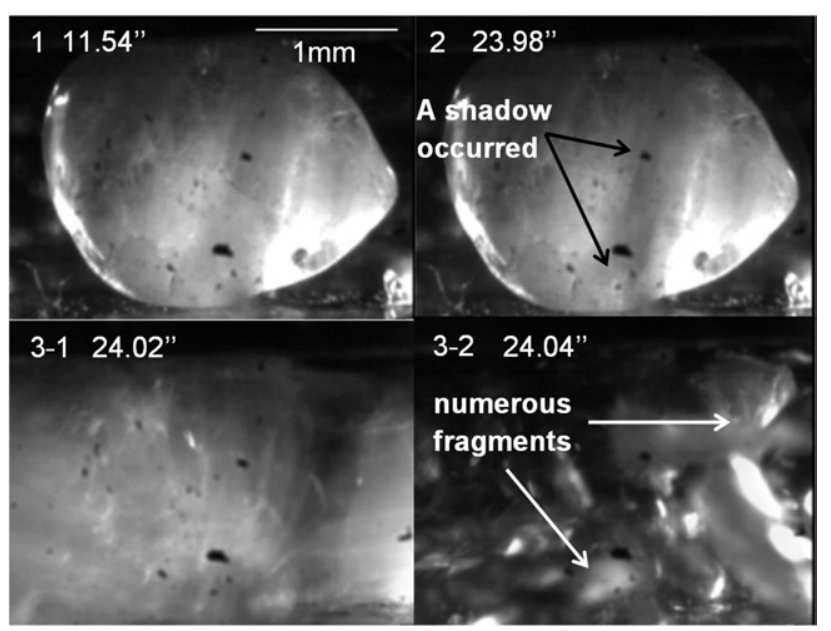

Fig. 8. A typical explosive mode failure for a LBS particle (1.18 2.36 mm, immersed)

\section{Mixed mode}

The mixed mode is when one smaller part of a particle explodes into many fragments with high velocity, but leaving the larger part remaining between the platens. This breakage mode is transitional between a typical splitting mode and a typical explosive mode, but more similar to the splitting mode. In Figs 13-15, the force-displacement curves along with the corresponding crushing processes of typical mixed modes for LBS and CDG particles are presented. Similarly to the splitting mode, the particle broke into two parts, but one relatively integral part remained through the loading axis whereas the other part exploded into many tiny fragments. Usually, the main body could support more loading after this failure leading to a second peak in the force-displacement curve. In Fig. 14, a shadow occurs in the centre right, below the contact area rather than at the contact surface. The area of the shadow enlarges, so that the crack extends to the contact surface and centre of the particle. From point 1 to point 3 in Fig. 13, the crack propagation was slow, but at the peak (point 4), the velocity of the propagation increased dramatically resulting in a catastrophic instantaneous failure of the particle. The CDG particle shows a similar behaviour (Fig. 15).

\section{Core-remaining mode}

A special breakage pattern termed 'core-remaining' was observed in a few instances, as shown in Fig. 16. As its name implies, the left and right parts of the particle explode into numerous fragments while a column-shaped core remains between the two platens at failure. Essentially it is an explosive mode and no cores were found for any splitting mode, including chipping and the mixed mode. This occurred in only six among 209 tests for LBS and two among 140 tests for CDG. It was perhaps less common in the CDG because the particles are composed of mineral aggregates and contained many more initial flaws. From an analysis of a section through spherical ballotini, Gallagher (1987) suggested that there could be an hourglass-shaped fracture path through the centre of a particle that possibly could result in a remaining core similar to that observed.

\section{Comparison of breakage modes in single particle and macroscopic tests}

In the literature various different breakage modes have been proposed. Tapias et al. (2015) suggested two breakage mechanisms for elastoplastic circular discs: local comminution or breakage of asperities, evolving to global splitting with the increase of external loading. The latter mode is similar to the splitting mode in this study, which indicated the particle divided into two major pieces, or as defined here a small number of pieces.

As discussed above, from their oedometer tests on quartz sand, Nakata et al. (2001b) defined five modes of

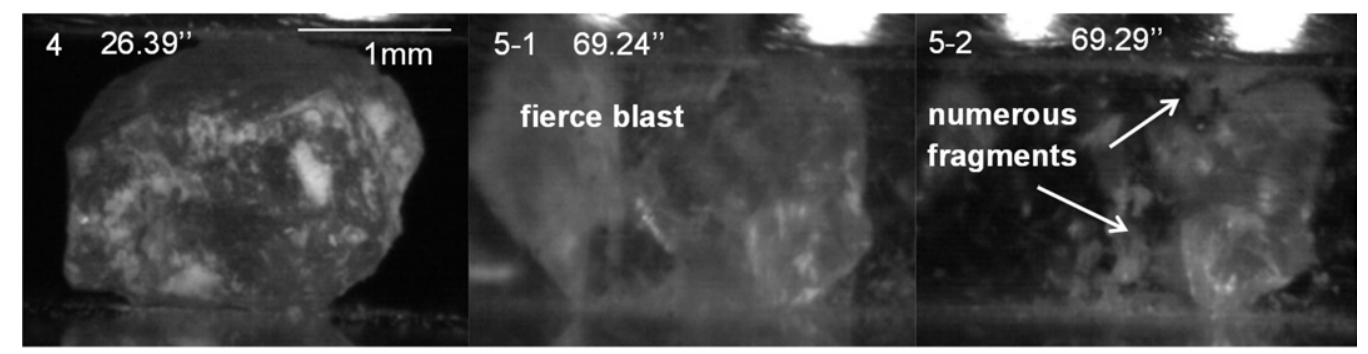

Fig. 9. A typical explosive mode failure for a CDG particle $(1 \cdot 18 \sim 2.36 \mathrm{~mm}$, dry) corresponding to Fig. 7 
breakage: no visible damage, single abrasion, more than one asperity fracture, major splitting and further breakage of sub-particles. These modes overlap and not all may occur for one test, depending on particle properties and loading histories, but they do tend to evolve from one to the next with increasing load. Abrasion cannot be resolved by the images produced here but is more likely at contacts loaded in shear, as might occur in an assembly, rather than in the normal loading of contacts in a single particle test. Comparisons of images from earlier and later stages of tests

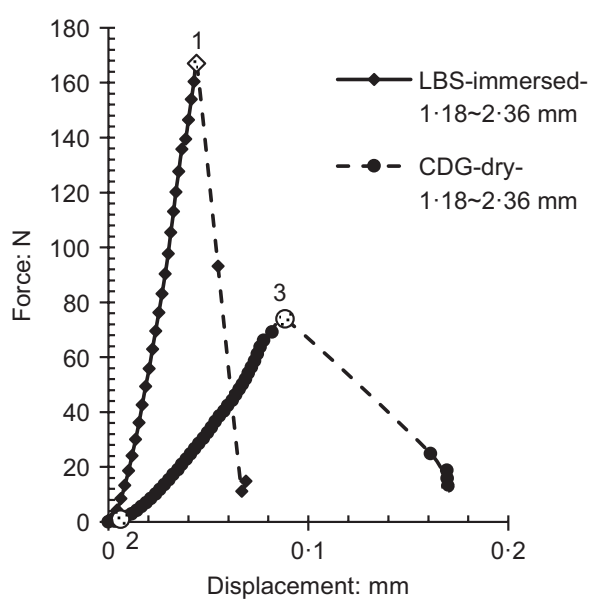

Fig. 10. Force-displacement curves of a typical chipping mode for a LBS particle $(1.18 \sim 2.36 \mathrm{~mm}$, immersed) and a CDG particle $(1 \cdot 18 \sim 2 \cdot 36 \mathrm{~mm}$, dry $)$ (e.g. Fig. 15 frames 5 and 7-4 or Fig. 11 frames 1-1 and 1-6) reveal a flattening of the contacts with the platens that may correspond to asperity breakage. The splitting mode of Nakata et al. (1999, 2001a, 2001b) is equivalent to that defined here, but further breakage of the sub-particles was not seen in these single particle tests because the tests were stopped after the peak load.

Although the splitting mode observed here might be similar to that of Tapias et al. (2015) or Nakata et al. (1999, 2001a, 2001b), the other modes might also be categorised as splitting and/or further breakage of sub-particles if the particles broke when they were in an assembly, because the broken pieces of an explosive mode would be restricted from dispersing and are likely to remain in close proximity. As discussed below, the particle breakage modes are also not solely a function of the loading stage, but depend on the internal microstructure of the particles (Zhao et al., 2015) as well as their shape, which has been investigated in the current work.

\section{The effect of test conditions on the particle strength}

Figure 17 shows the effect of immersion on the strengths. For both the LBS and CDG particles the two curves for the particle survival probability in dry and immersed conditions are very similar, indicating that the water effect on single particle compression strength is not significant. This is perhaps a surprising result in light of the work of Coop \& Lee (1995) and Oldecop \& Alonso (2001, 2003), which indicated that sand particles tend to be weaker in a wet condition. For the LBS it can perhaps be understood because the particles have few initial defects either inside or on the surface of the grain (Zhao et al., 2015), so intra-particle suctions

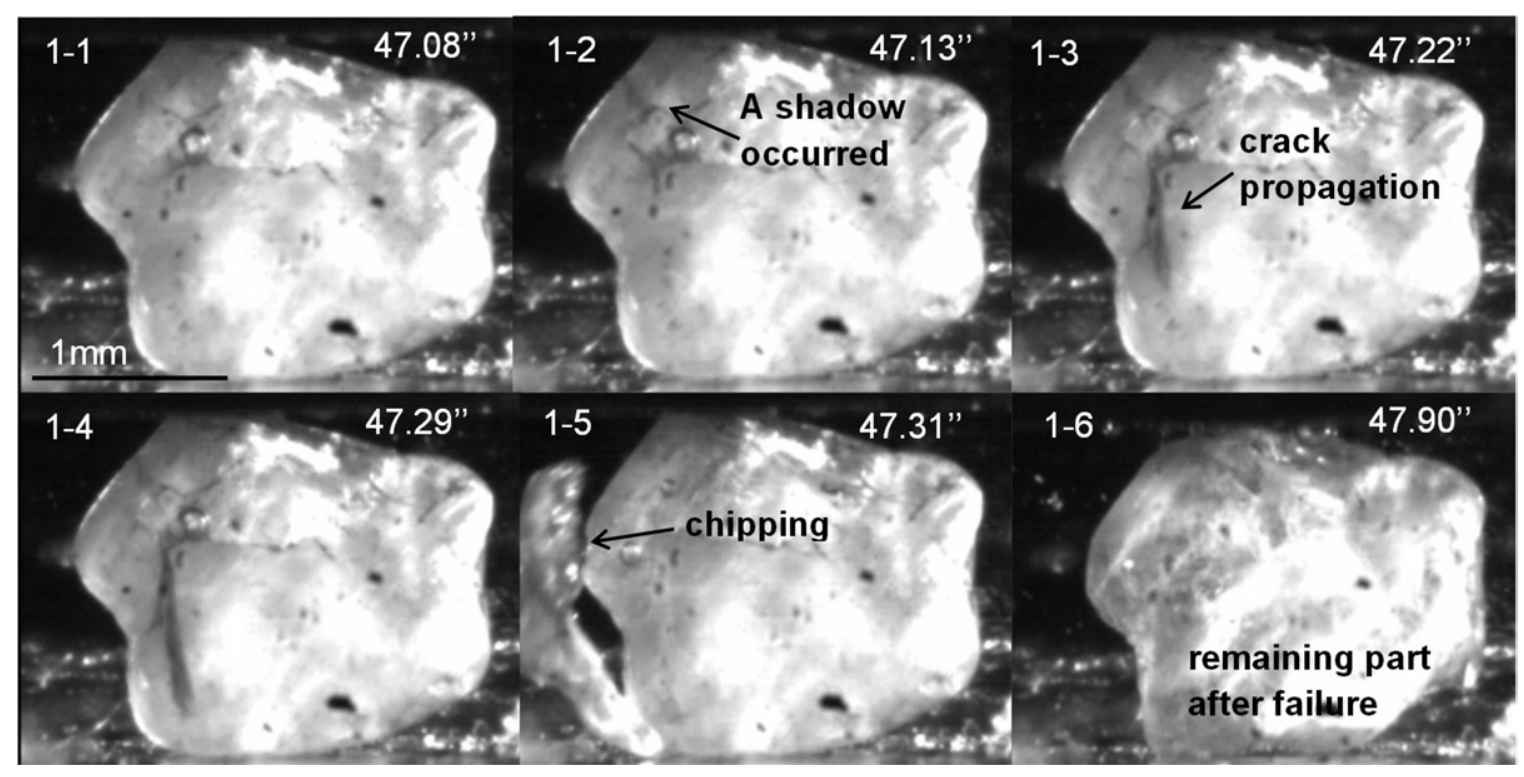

Fig. 11. A typical chipping mode failure process for a LBS particle $(1 \cdot 18 \sim 2 \cdot 36 \mathrm{~mm}$, immersed) corresponding to Fig. 10

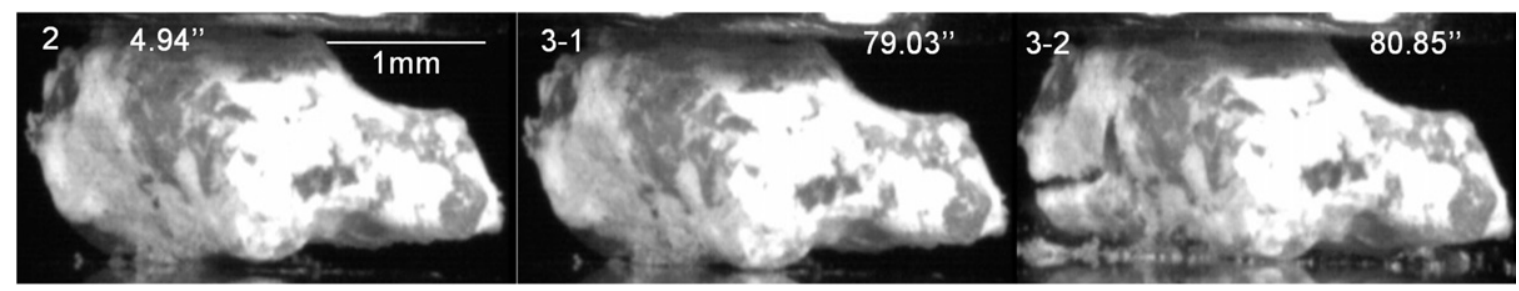

Fig. 12. A typical chipping mode failure process for a CDG particle $(1 \cdot 18 \sim 2 \cdot 36 \mathrm{~mm}$, dry) corresponding to Fig. 10 
are unlikely, as Coop \& Lee $(1993,1995)$ had suggested, or alternatively stress corrosion within internal cracks is less likely, as suggested by Oldecop \& Alonso (2001, 2003). Especially, for the CDG, the micro-fissures in the particles and the presence of significant amounts of clay minerals

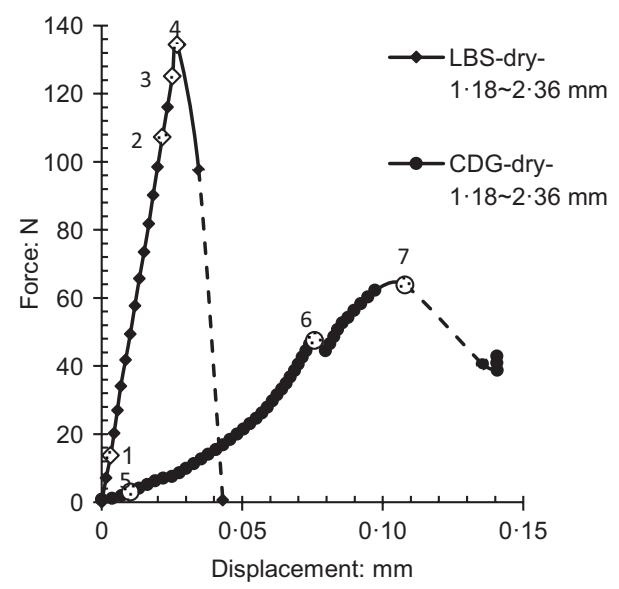

Fig. 13. Force-displacement curves of a typical mixed mode for a LBS particle $(1.18 \sim 2.36 \mathrm{~mm}$, dry $)$ and a CDG particle $(1 \cdot 18 \sim 2 \cdot 36 \mathrm{~mm}$, dry $)$ in the aggregates might have been expected to give higher strengths in the dry condition, in line with the data of Coop \& Lee $(1993,1995)$.

The effect of breakage modes on the particle strength

Figure 18 presents a comparison of the particle strengths in the splitting and explosive modes for the two different materials and for two sizes of LBS. Here the term splitting mode is used broadly to include not only the splitting described above, but also the chipping and mixed modes, because the data were not separable. The data for dry and immersed conditions have also been combined, as no significant difference between them could be found, although no immersed tests were carried out for the larger size of LBS. In each case the particle strength for the splitting mode is lower than that for explosive mode. The higher strength and so greater energy stored from the external load in the explosive mode corresponds to the creation of a large number of fragments with a much greater surface area and with high kinetic energy, dissipating that energy on failure. The difference between the two modes is smaller for the CDG, perhaps as a result of the effects of the looser and weaker structure and more irregular shape on the mechanical response. The data also confirm the findings of Nakata et al. (1999) that the characteristic strength decreases as particle size increases. For the LBS the characteristic strength for the

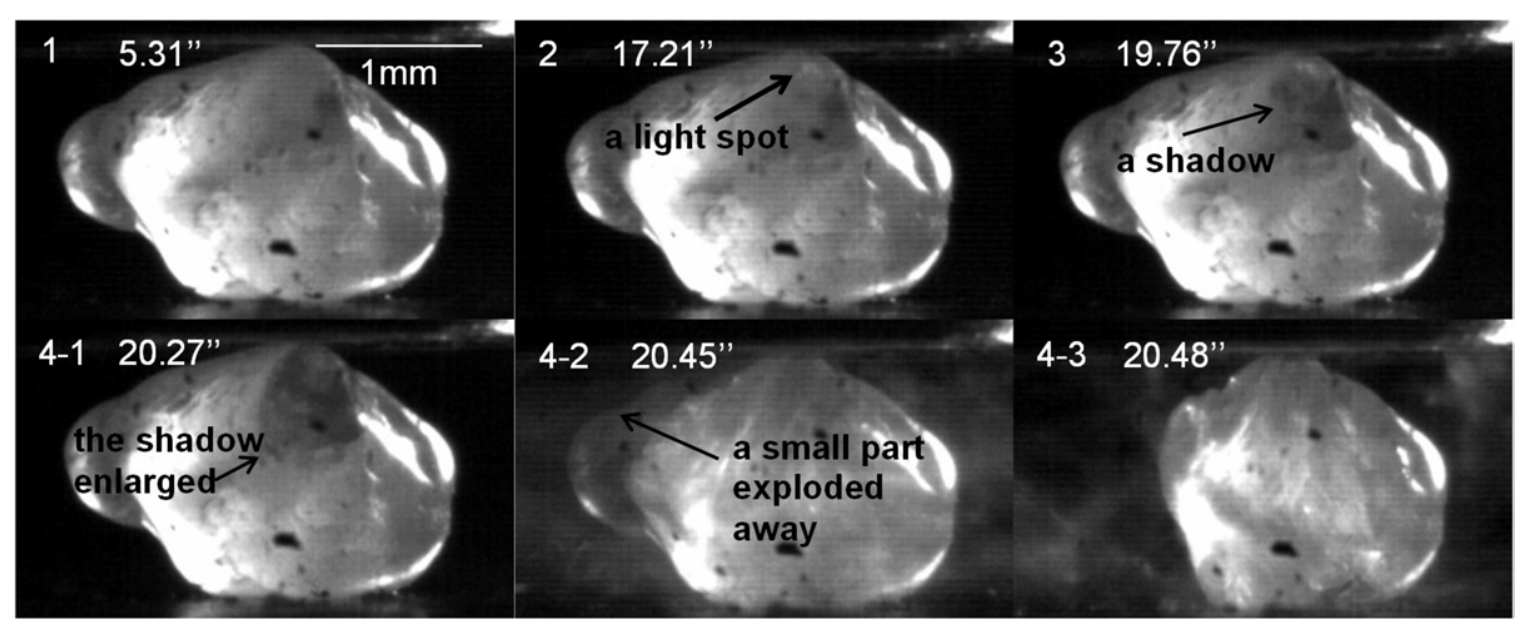

Fig. 14. A typical mixed mode failure for a LBS particle $(1 \cdot 18 \sim 2.36 \mathrm{~mm}$, dry $)$ corresponding to Fig. 1

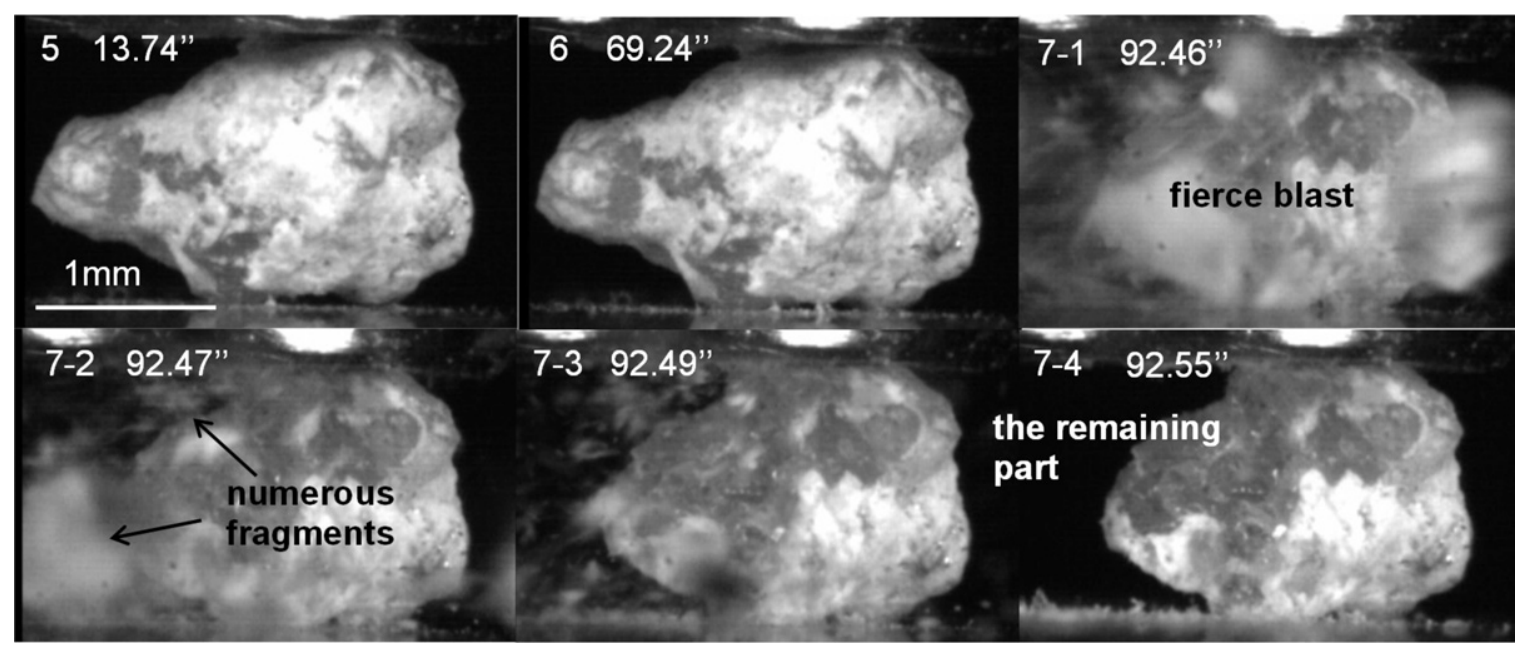

Fig. 15. A typical mixed mode failure for a CDG particle (1.18 $\sim 2.36 \mathrm{~mm}$, dry) corresponding to Fig. 13 


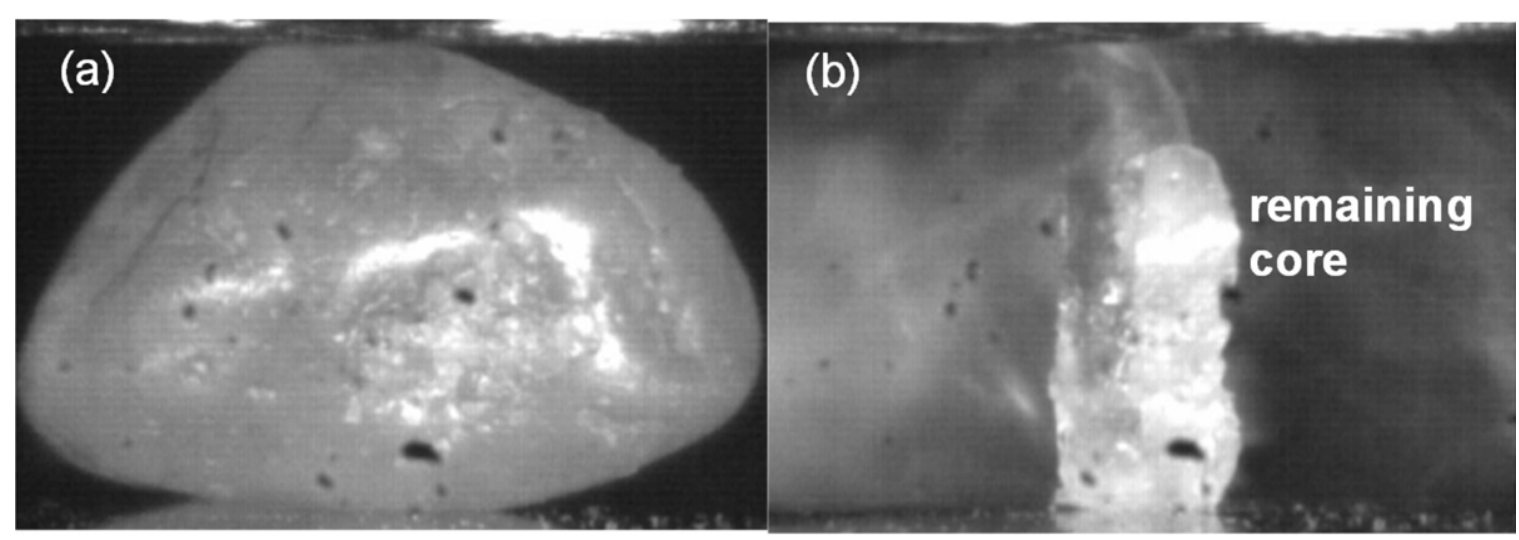

Fig. 16. A typical core-remaining breakage pattern for a LBS particle $(1 \cdot 18 \sim 2 \cdot 36 \mathrm{~mm}$, dry)

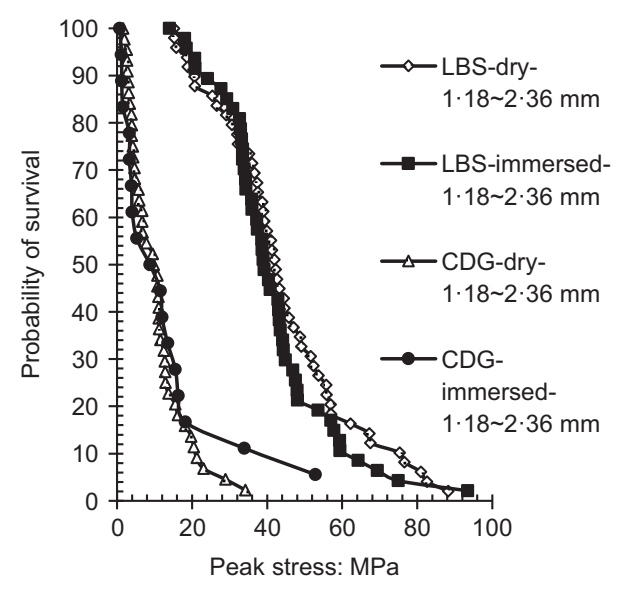

Fig. 17. The effect of water on particle strengths: LBS particles $(1 \cdot 18 \sim 2 \cdot 36 \mathrm{~mm})$ and CDG particles $(1 \cdot 18 \sim 2 \cdot 36 \mathrm{~mm})$

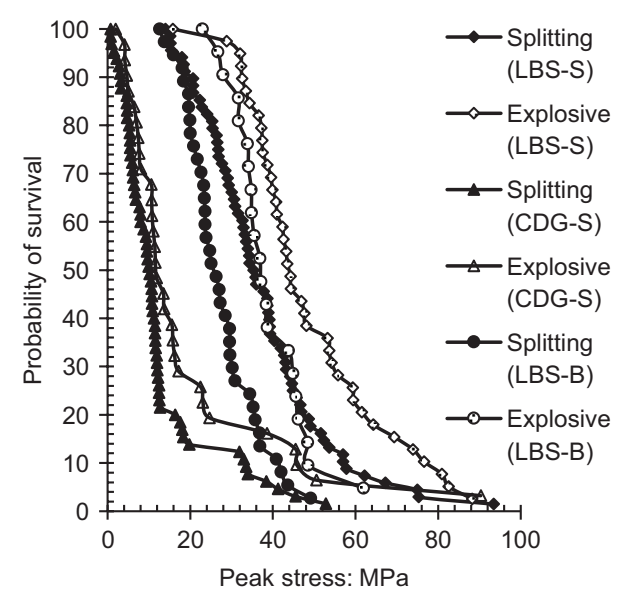

Fig. 18. Comparison of single particle strengths between two breakage modes: splitting and explosive modes for LBS and CDG particles and different particle sizes. $S$, small size $1.18 \sim 2.36 \mathrm{~mm}$; B, big size $2 \cdot 36 \sim 5 \cdot 00 \mathrm{~mm}$

small particles $(1 \cdot 18 \sim 2 \cdot 36 \mathrm{~mm})$ including both splitting and explosive modes is $47 \mathrm{MPa}$, whereas it is $33 \mathrm{MPa}$ for the large particles $(2.36 \sim 5.00 \mathrm{~mm})$. The figure shows that the effect of size applies to both modes of breakage.

Histograms of the strain at failure for LBS and CDG particles $(1.18 \sim 2.36 \mathrm{~mm})$ are shown in Fig. 19. The strain used is a nominal strain defined as the ratio of the particle deformation along the loading axis during compression to the initial height of the particle $\left(d_{3}\right)$. For the LBS the mean nominal strain for the explosive mode is significantly higher than that for splitting mode, but for the CDG there is no clear trend for the strain changing with the different failure modes, corresponding to the much smaller effect on strength. For the LBS particles in splitting, the mean strain at failure is $1.6 \%$ while the mean strength is $37 \cdot 3 \mathrm{MPa}\left(\sigma_{0}=39 \cdot 3 \mathrm{MPa}\right)$, whereas in the explosive mode they are $2.5 \%$ and $48.6 \mathrm{MPa}$, respectively $\left(\sigma_{0}=51 \cdot 2 \mathrm{MPa}\right)$, so the strain at failure is largely explained by the different strengths. The degree of violence of the failure therefore seems to depend on what strength is reached, which is probably related to different internal structures and mineralogies (Zhao et al., 2015) and different external shapes, as discussed below.

To investigate the strength difference between two breakage modes for particles with different sizes, in Fig. 20 the peak stress $\sigma_{\mathrm{p}}$ data for the LBS are normalised by dividing by the characteristic strength $\sigma_{0}$ in the splitting mode for each particle size. This choice of normalising with respect to the $\sigma_{0}$ of the splitting mode is arbitrary and is merely to eliminate the effect of size on particle strength, making the strength differences between the modes more easily comparable and highlighting that the difference between the splitting and explosive modes is much greater for the larger particle size. However, in Fig. 21 it is clear that the percentage of each failure mode only depends on the sand type, LBS or CDG, rather than on the test conditions or particle size, the explosive mode being less common in the weaker CDG.

\section{The effect of mineralogy on the particle strength}

The CDG sands used in this study consist of potassium feldspar (32\% by weight), quartz (30\%), amorphous content $(23 \%)$, illite/muscovite $(9 \%)$ and sodium plagioclase $(6 \%)$ (Rocchi, 2014; Rocchi \& Coop, 2015). However, as was highlighted by Lee \& Coop (1995) the internal structure of CDG particles is complex, typically comprising agglomerates of different minerals, some inherited from the parent rock and some the products of weathering. Internal micro-fissures also result from the weathering processes. Through their CT scanning Zhao et al. (2015) investigated the strengths of slightly less weathered particles of the same soil as tested here (HDG, highly decomposed granite) and concluded that the strength was indeed affected by the internal mineral boundaries and micro-fissures along with the cleavages that are present in some of the minerals. It was also noticed for this more weathered CDG that clay minerals tended to coat the surfaces of the particles. In contrast, Zhao et al. (2015) showed that the LBS particles have a compact microstructure with few internal defects and, as quartz has no cleavage, 


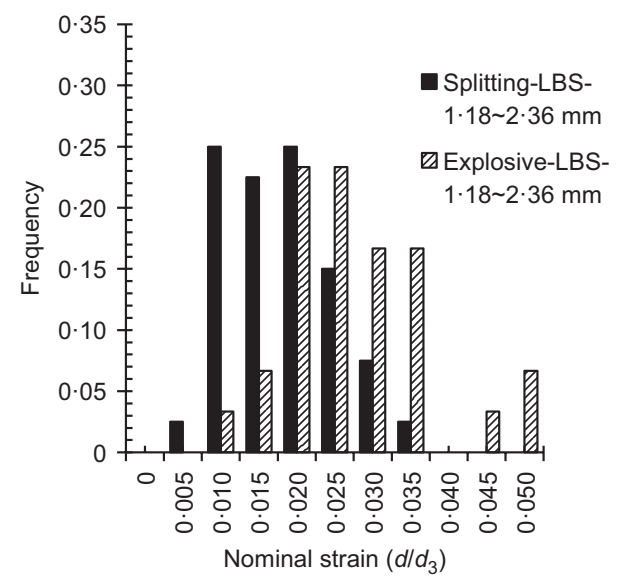

(a)

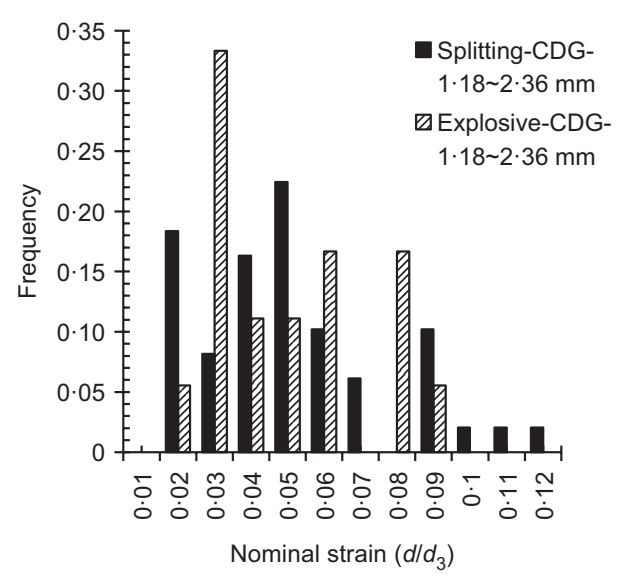

(b)

Fig. 19. Frequency distribution of nominal strain for splitting and explosive failure modes: (a) LBS, 1·18 2.36 $\mathrm{mm}$; (b) CDG, 1·18 $\sim 2 \cdot 36 \mathrm{~mm}$

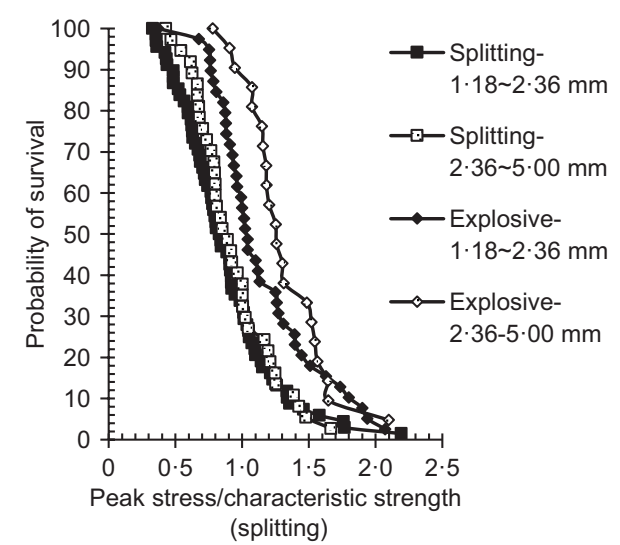

Fig. 20. Effect of particle size on strength for different breakage modes for LBS

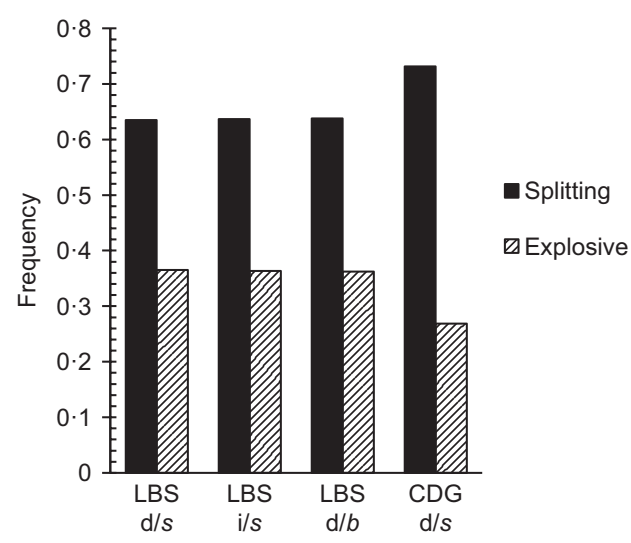

Fig. 21. Proportion of splitting and explosive mode for different materials: LBS and CDG; different particle size: $s=1 \cdot 18 \sim 2.36 \mathrm{~mm}$, $b=\mathbf{2 . 3 6} \sim \mathbf{5 . 0 0} \mathrm{mm}$; different test conditions: d, dry; i, immersed

failures tended to be simple and conchoidal in nature. Using the high-speed camera adopted here the internal structure of each particle is unknown, but because the number of particles that can be tested is much larger, statistical parameters describing the strength distribution can be derived. Figs 17 and 18 emphasise the weaker nature of the CDG that should be expected from the prevalence of internal defects, whereas Fig. 22 shows that the variability of strength is also much

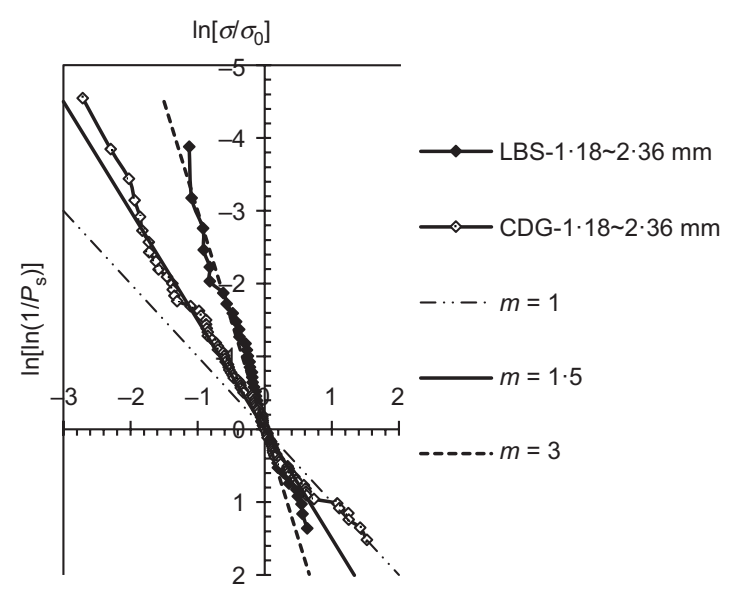

Fig. 22. Weibull moduli $\boldsymbol{m}$ for LBS and CDG $(1 \cdot 18 \sim 2 \cdot 36 \mathrm{~mm})$

higher, as expected from the greater variability of internal structure. The Weibull modulus $m$ is around 3 for $\sigma<\sigma_{0}$ and 1.5 to 3 for $\sigma>\sigma_{0}$ for the LBS, whereas for the CDG sand, the $m$ value is about 1.5 for $\sigma \leq \sigma_{0}$ and 1 to 1.5 for $\sigma>\sigma_{0}$.

\section{THE EFFECT OF PARTICLE MORPHOLOGY ON STRENGTH \\ Local roundness}

Roundness is a parameter used to describe the degree of sharpness of a particle, introduced by Wadell (1932, 1933, 1935). It is defined as a ratio of the average radius of all the corners to the radius of the maximum inscribed circle, but it is influenced by the scale of measurement. The measurement does not take surface concavities into consideration, which are not common but do exist for natural particles. Brzesowsky et al. (2011) investigated the effect of the equivalent radius of curvature on the particle critical force at failure. The equivalent radius accounts for the maximum and minimum radii of curvature on the contact surface. Here, a local roundness LR at the contacts will be used, defined as follows

$$
\text { Local roundness }=\frac{r_{\mathrm{c}}}{R_{\text {ins }}}
$$

where $r_{\mathrm{c}}$ is the local radius of curvature at either of the contact surfaces and $R_{\text {ins }}$ is the radius of the maximum inscribed circle of the particle outline, so a contact surface with a high local roundness means it is flatter. The outline 
of a particle is fitted by polynomial functions as $f(x)$ using Matlab after an image binarisation processing. Then the radius of curvature for one contact point is calculated by

$$
\rho=\frac{\left[1+f^{\prime 2}(x)\right]^{3 / 2}}{\left|f^{\prime \prime}(x)\right|}
$$

and $r_{\mathrm{c}}$ is the average value of $\rho$ for the whole contact region so that $r_{\mathrm{c}}=\sum_{i=1}^{n} \rho_{i} / n$. The Matlab code also calculated the maximum inscribed circle and minimum circumscribed circle of the particle outline as shown in Fig. 23. In each case the minimum local roundness is used out of the values for the upper and lower contacts and for the two orthogonal views, where available.

Figure 24(a) illustrates the relationships between local roundness and characteristic strength for different failure modes. The error bar for local roundness shows the standard deviation. The results show that the particles with higher

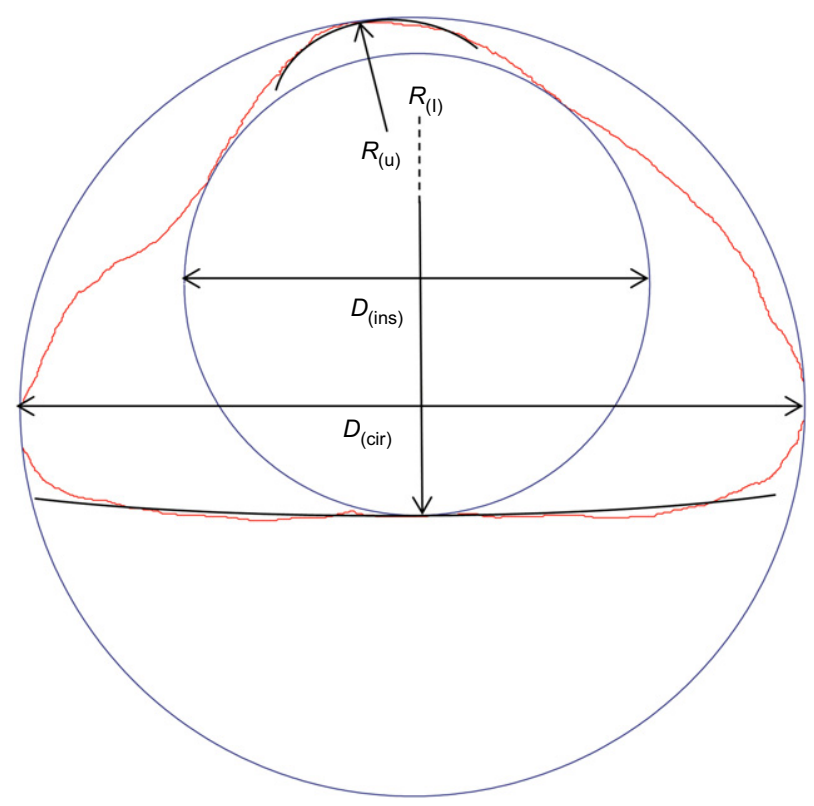

Fig. 23. Schematic diagram showing the measurement of minimum local roundness. $D_{\text {(ins) }}$, diameter of minimum inscribed circle; $D_{(\text {cir) }}$, diameter of maximum circumscribed circle; $\boldsymbol{R}_{(\mathrm{u})}$, radius of upper contact surface; $\boldsymbol{R}_{(\mathbf{l})}$, radius of lower contact surface local roundness tend to crush in an explosive mode with a higher $\sigma_{0}$ regardless of the sand type or particle size. This could be explained by stress concentrations at the contact points. For rounded or sub-rounded particles, less stress concentration occurs within the contact area owing to the flatness of the contact surface. The greater strength that this induces leads to greater stored energy, released more violently at failure. In contrast, for angular or sub-angular particles, failure may be initiated at an earlier stage around asperities leading to lower strengths and a tendency towards splitting instead of an explosive failure.

All the values of local roundness in Fig. 24(a) were obtained from images from the 'frontal' direction, that is, the view from the high-speed microscope camera. For the LBS of $2.36 \sim 5.00 \mathrm{~mm}$ size the local roundness was also measured from the perpendicular direction. A 'three-dimensional (3D)' local roundness could then be defined from the minimum value of either upper or lower contacts defined from either orthogonal direction. This is compared with the frontal view two-dimensional (2D) values in Fig. 24(b), but there is not much difference for either failure mode.

\section{Equancy, 2D sphericity and regularity}

As suggested by Blott \& Pye (2008), the degree of equancy is defined by the ratio of $S / L$, where $S$ is the shortest dimension and $L$ is the longest dimension of a particle. As a combination of flatness and elongation, equancy is used to describe the particle form and is similar to an aspect ratio. Fig. 25(a) shows that the degree of equancy of a particle does not influence the particle strength or particle failure mode.

Wadell (1932) proposed sphericity to describe a particle shape, which reflects how a particle shape approximates to a true sphere. For 2D particle images, the circle ratio sphericity calculated from $D_{\text {ins }} / D_{\text {cir }}$ has been used here, as reviewed by Zheng \& Hryciw (2015), where $D_{\text {ins }}$ is the diameter of the maximum inscribed circle and $D_{\text {cir }}$ is the diameter of the minimum circumscribed circle. In Figs 25(b) and 25(c) the density distributions have been drawn for three ranges of 2D sphericity based on the two orthogonal views, defined either as major or minor planes depending on their dimensions.

The ordinate values of the peaks of the curves indicate the maximum frequencies and the abscissa values of the peaks indicate the mean $\sigma_{\mathrm{p}}$ values (assuming the distributions are normal) for the different $2 \mathrm{D}$ sphericity ranges. For the

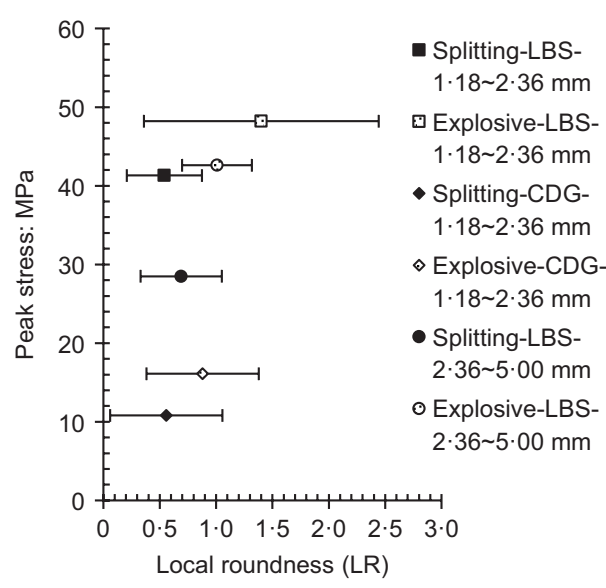

(a)

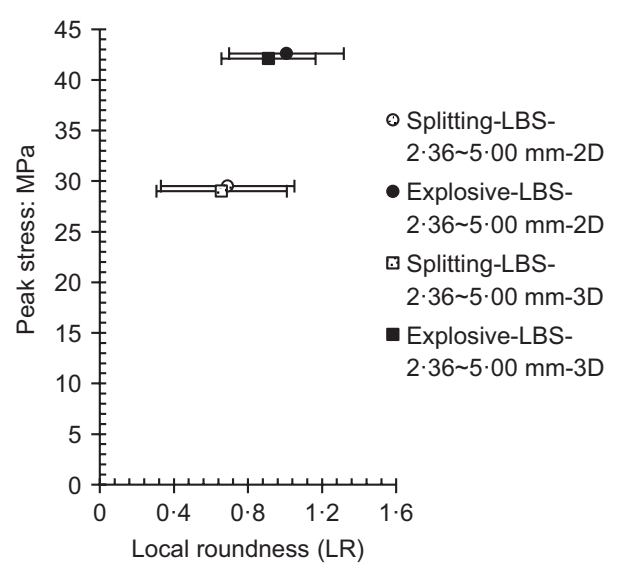

(b)

Fig. 24. (a) Relationship between local roundness $\left(R_{\text {cir }}\right)$ and characteristic strength. (b) Comparison of the values of local roundness $\left(R_{\text {cir }}\right)$ between 2D and 3D measurements. (For illustrative purposes the same characteristic strength for each failure mode has been separated artificially) 


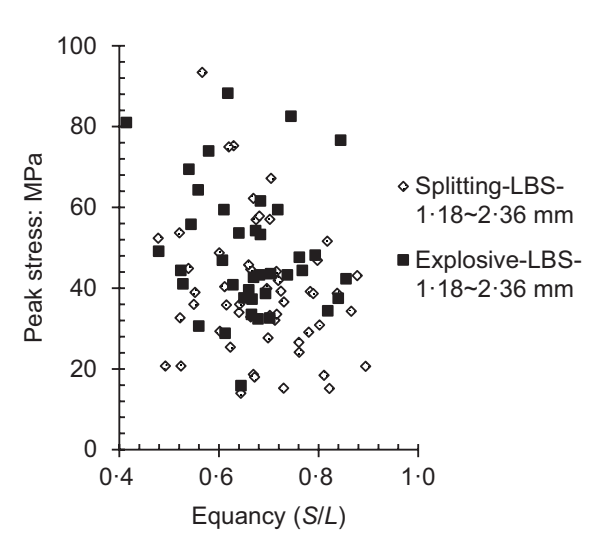

(a)

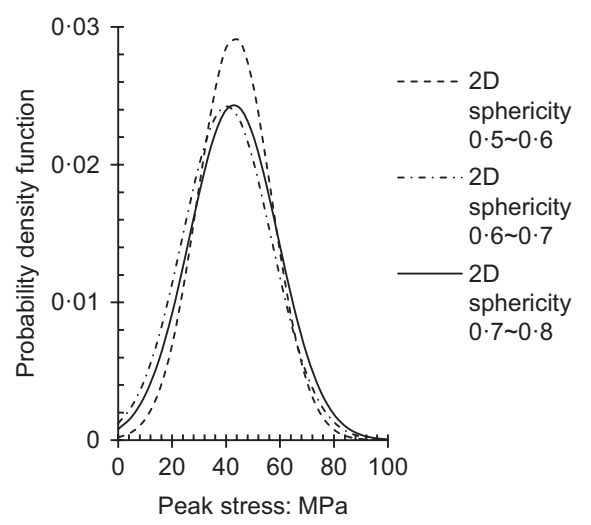

(c)

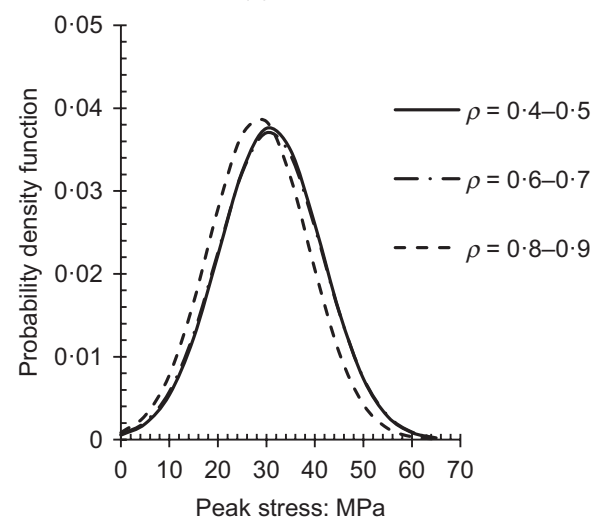

(e)

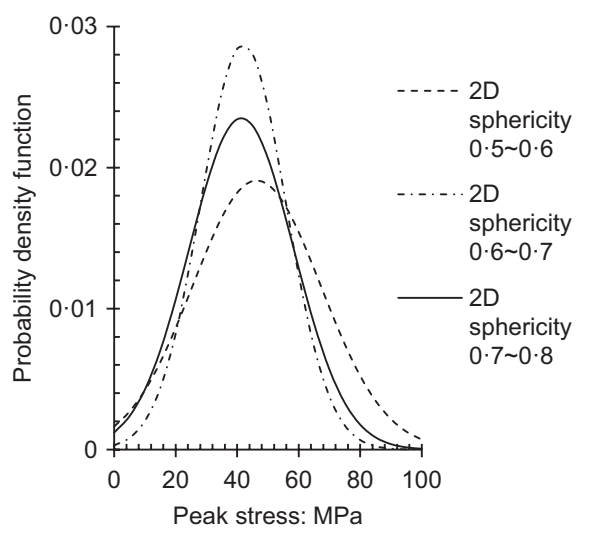

(b)

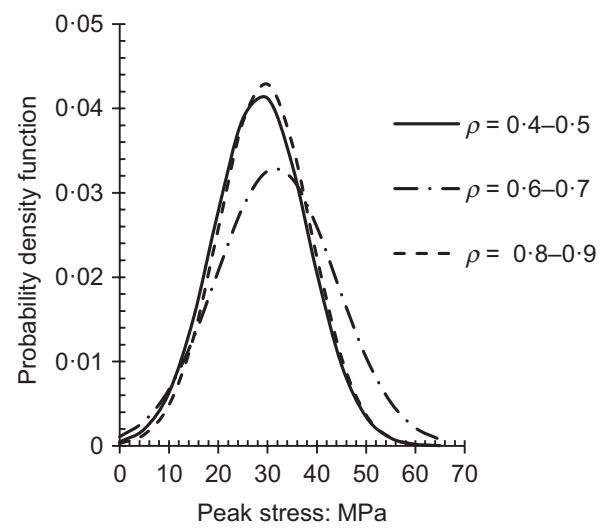

(d)

Fig. 25. Effect of particle morphology on strength: (a) effect of the equancy; (b) and (c) effect of 2D sphericity for LBS (1·18 $\sim 2 \cdot 36$ mm) (image of major plane (b) and minor plane (c)); (d) and (e) effect of regularity of LBS (2.36 $\sim 5 \cdot 00$ mm) (image of major plane (d) and minor plane (e))

major plane (Fig. 25(b)) the mean $\sigma_{\mathrm{p}}$ values are nearly identical and for the minor plane (Fig. 25(c)) the mean values are quite similar and show no consistent trend. The standard deviations are also quite similar for both the major plane and minor plane, but peak frequencies vary much more for the major plane than that for the minor plane. The particle strength is therefore not significantly and consistently affected by this global shape characteristic.

A similar conclusion can be made for regularity $\rho$, proposed by Cho et al. (2006), which combines the values of roundness and sphericity

$$
\rho=\frac{\text { roundness }+ \text { sphericity }}{2}
$$

Here the values of roundness were obtained from the chart of Krumbein \& Sloss (1963). The density distributions in Figs 25(d) and 25(e) show that the regularity also has little influence on particle strength, with very similar values of mean, peak frequency and standard deviation for all regularities except $\rho=0.6-0.7$ for the major plane, but there are again no consistent trends. In summary, the results confirm that a local shape descriptor like local roundness has a significant impact on particle mechanical characteristics but global shape descriptors such as the degree of equancy (or aspect ratio), 2D sphericity or regularity do not.

From a macro-mechanical point of view, Liu et al. (2005) investigated numerically the inter-particle breakage process under confined conditions. The results revealed that the particle shape had an important influence on the contact conditions between particles and the breakage mechanisms within an assembly. For circular particles, the fragmentation would start within the smaller particles of the assembly, but for irregular particles those contacting the loading boundaries were first to break. The latter conclusion is in agreement with the observation made here that more angular 
particles in contact with a rigid platen are vulnerable to breakage.

\section{CRACK INITIATION LOCATION}

For many of the tests the crack initiation point inside the particle could be observed using the high-speed microscope camera, especially for the LBS, the particles of which are translucent. The initial crack location area was defined as either a shadow or a bright region within the image, depending on the lighting conditions, which indicated that a crack was initiating within the particle. If the intensity of the shadow or bright area was uniform, the centre of this area was defined as the initial crack point. An example is shown in
Fig. 26. If the intensity of the shadow or bright area was non-uniform, the darkest (or brightest) point was considered as the initial crack location, as shown in Fig. 27. The crack initiation point could not be observed in every test and if it was not clear, or was hard to define, the data were excluded in this study.

This technique is limited to a $2 \mathrm{D}$ frontal view of that location. Horizontal and vertical location ratios are used to describe the location. The horizontal location ratio is defined as the ratio of the distance of the crack initiation point from the loading axis, $r_{1}$, to half of the particle height, that is $r_{1} / d_{3} / 2$ (Fig. 28(a)). The value of the horizontal location ratio is considered negative if it occurs on the short side of the loading axis and positive on the long side. The vertical

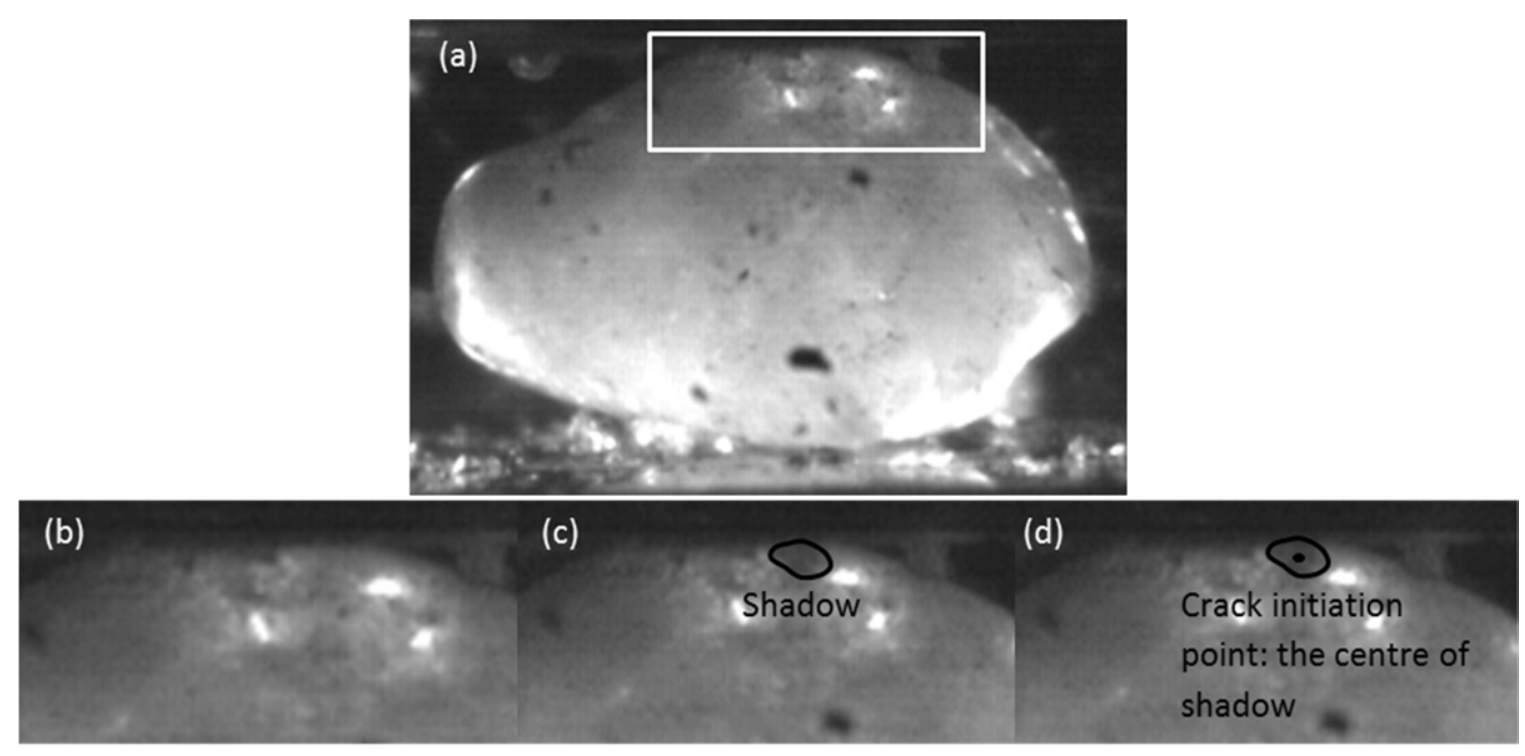

Fig. 26. Definition of crack initiation point for a uniform shadow within the particle
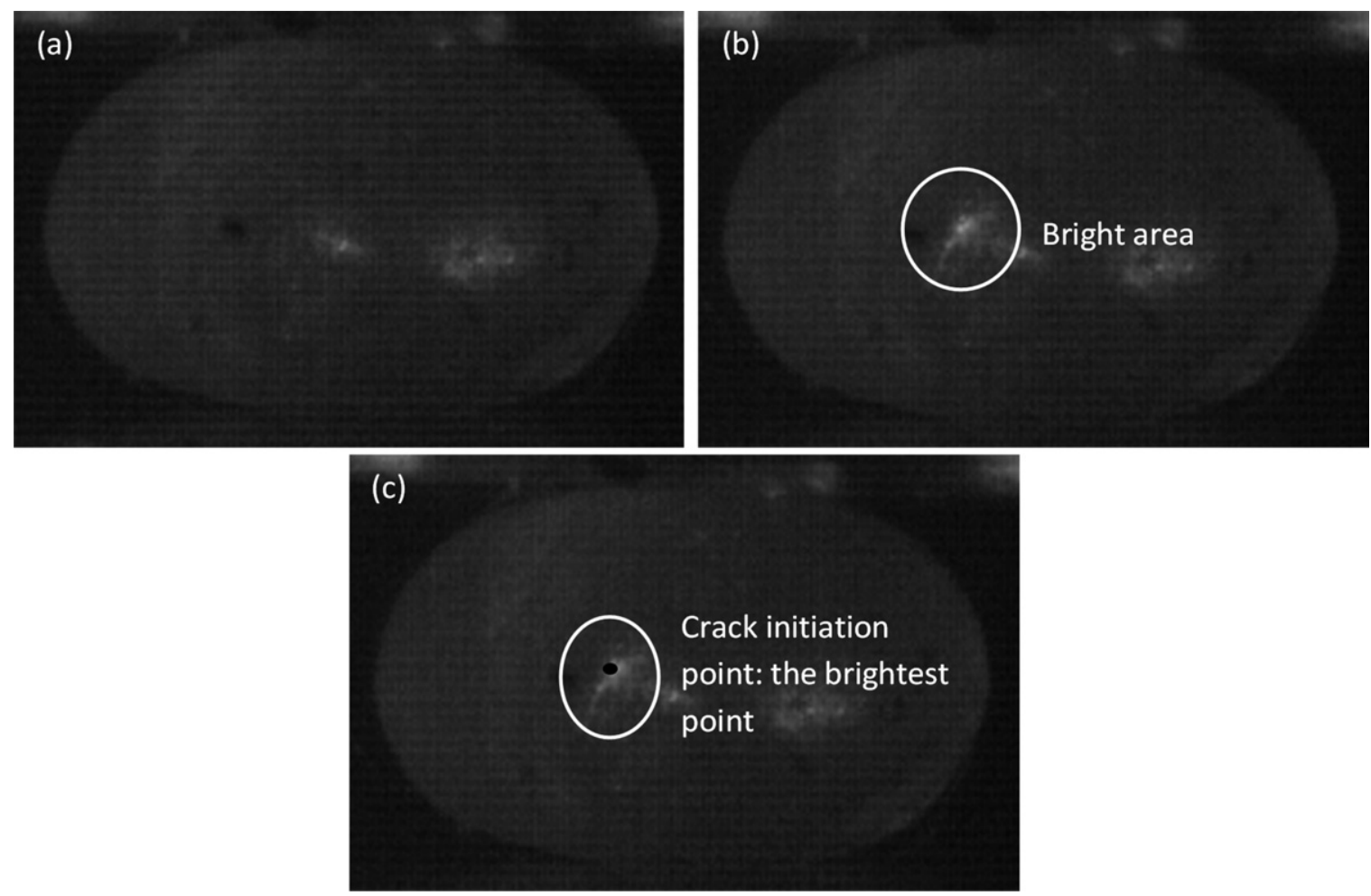

Fig. 27. Definition of crack initiation point for a non-uniform bright area within the particle 
location ratio is defined as the ratio of the distance of the point from the central axis, $r_{2}$, to half of the particle height, that is, $r_{2} / d_{3} / 2$. If the crack initiation point occurs above the centreline, the value is positive.

Figure 28(b) illustrates the distribution of crack initiation points for LBS $(1 \cdot 18 \sim 2.36 \mathrm{~mm})$, where it can be seen that the initiation points concentrate just below the upper contact surface. This observation is consistent with the conclusion of Russell \& Wood (2009), who also suggested that a natural particle tends to fail in the upper contact region because there is generally only one contact point there, whereas there must be at least three contact points initially on the lower surface to keep the particle standing, leading to a confinement effect and more complex stress field in the lower part. However, this tendency is less clear for the larger LBS particles $(2.36 \sim 5.00 \mathrm{~mm})$ in Fig. 28(c). Similarly, the distribution of crack initiation points for CDG (Fig. 28(d)) is erratic, probably as a result of its complex internal structure.

The conclusion is confirmed by the histograms in Figs 29 and 30. The crack initiation points for the LBS $(1.18 \sim 2.36 \mathrm{~mm})$ tend to concentrate in a smaller region within the horizontal location ratio values $-0 \cdot 2$ to $+0 \cdot 4$, while they are within a wider region from -0.6 to +1.0 for the CDG (Fig. 29(a)). For the LBS, in the vertical direction the highest frequency of crack initiation locations occurs at a vertical location ratio of $+0 \cdot 9 \sim+1 \cdot 0$ and the second highest frequency, although much less common, occurs at a ratio of $-0 \cdot 9 \sim-1 \cdot 0$. The frequency then decreases from both sides towards the centre. For the CDG particles, the frequency distribution of crack initiation locations along the vertical direction is more uniform. Fig. 30 shows a comparison of the frequency of crack initiation locations for LBS particles with different sizes. Much like the results for the CDG sands, for the larger LBS particles $(2.36 \sim 5.00 \mathrm{~mm})$ the crack initiation location in the horizontal direction varies more widely from about -0.6 to +0.8 and the crack initiation location in the vertical direction distributes more uniformly.

\section{CONCLUSIONS}

A series of single particle uniaxial compression tests using a high-speed microscope camera were conducted to investigate the micro-mechanics of natural sand particle crushing. Two different materials, LBS and CDG were tested, the former with different grain sizes, $1.18 \sim 2.36 \mathrm{~mm}$ and $2.36 \sim 5.00 \mathrm{~mm}$. Four failure modes could be described: splitting, explosive, chipping and a mixed mode, based on visual inspection of the violence of the failure and the number of fragments created. The chipping and mixed modes were believed to be variants of the splitting mode. Immersion of both sands revealed little effect on the single particle strength or mode of breakage. Particles failing in the

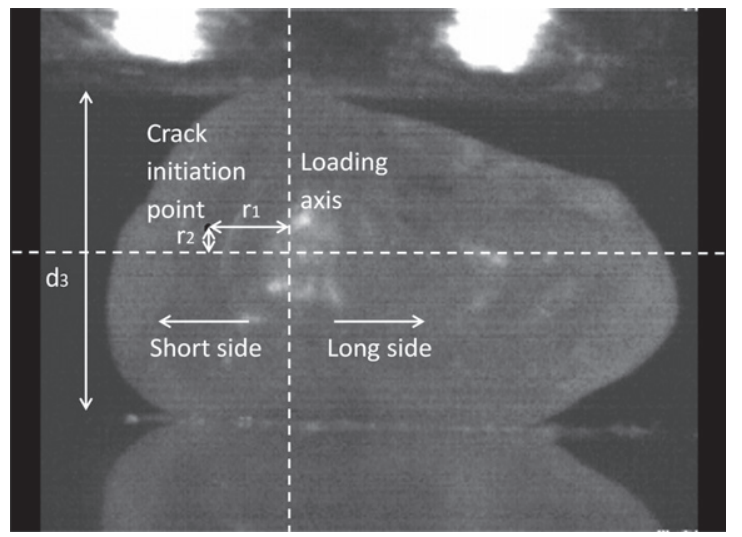

(a)

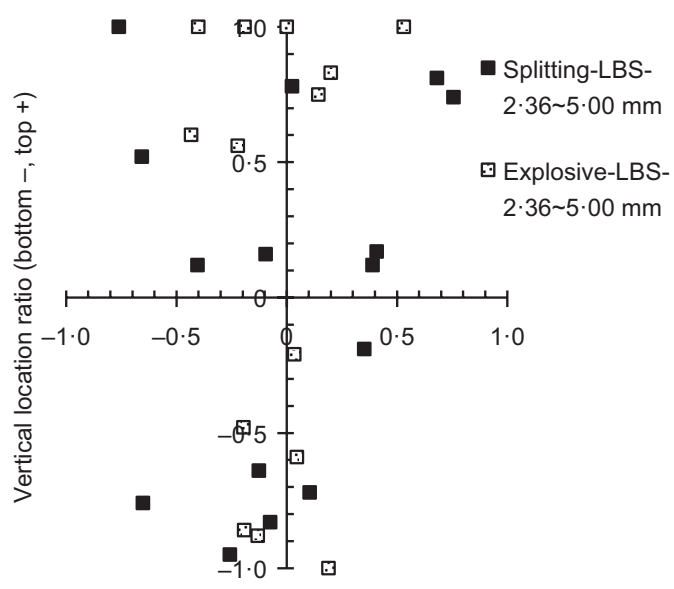

Horizontal location ratio (short side -, long side + )

(c)

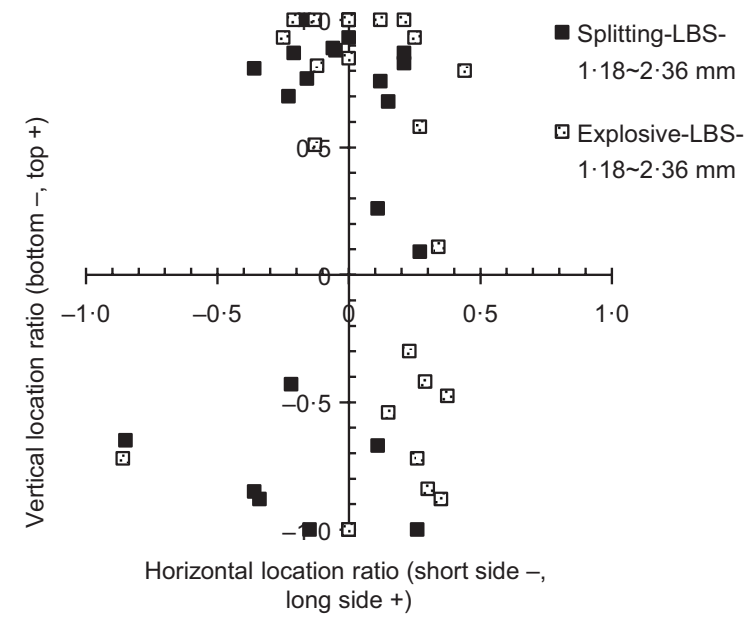

(b)

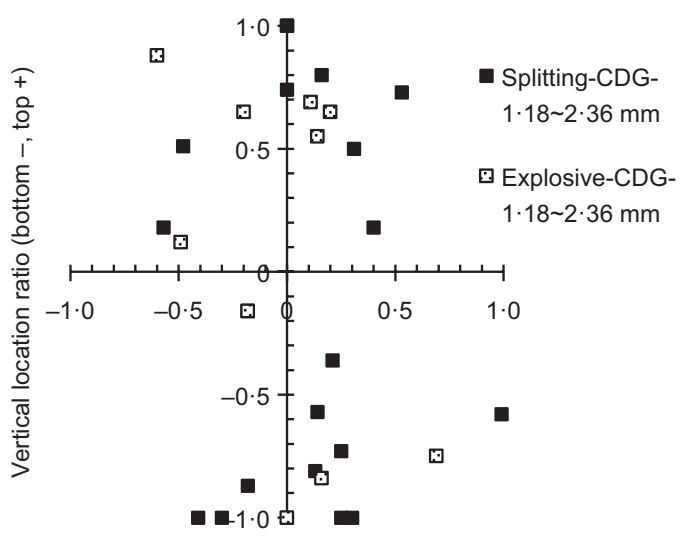

Horizontal location ratio (short side -, long side + )

(d)

Fig. 28. Initiation location of cracks inside particles for different failure modes: (a) definition of location ratio; (b) LBS 1.18 2.36 mm; (c) LBS 2.36 5.00 mm; (d) CDG 1.18 $\sim 2.36 \mathrm{~mm}$ 


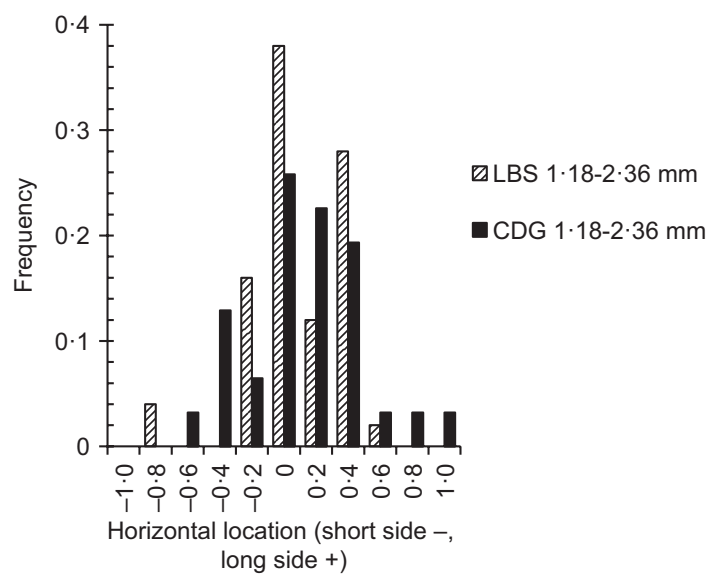

(a)

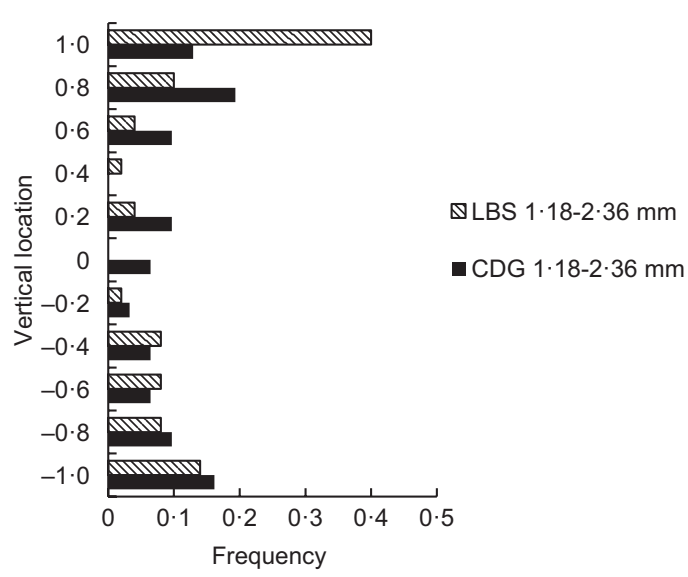

(b)

Fig. 29. Comparison of crack initiation locations for the LBS and CDG of $1.18 \sim 2.36 \mathrm{~mm}$ size, in (a) the horizontal direction and (b) the vertical direction

explosive mode tended to be stronger with more deformation at failure than those failing in any of the splitting modes, because of the greater energy stored inside the particles.

A local shape descriptor termed local roundness has been defined to characterise the contacts, and the results show that the particles with higher local roundness, that is, flatter contact surfaces with the loading platens, tend to break in an explosive mode with higher strength, whereas those with lower roundness tend to split. A possible interpretation is that cracks tend to initiate prematurely at sharp contacts due to stress concentrations for particles with low local roundness. Global shape parameters such as degree of equancy (or aspect ratio), 2D sphericity or regularity have little influence on the strength of single particles. In many cases the crack initiation locations inside the particles could be detected by the high-speed microscope camera. For the small LBS particles the crack initiation points concentrated more in the central upper part, near the contact surface and the initiation location frequency decreases from both top and base towards the middle along a vertical direction. However, these tendencies are less clear for the CDG and the larger LBS particles.

\section{ACKNOWLEDGEMENT}

The work described in this paper was fully supported by a grant from the Research Grants Council of the Hong Kong Special Administrative Region, China (project no. CityU 112712).

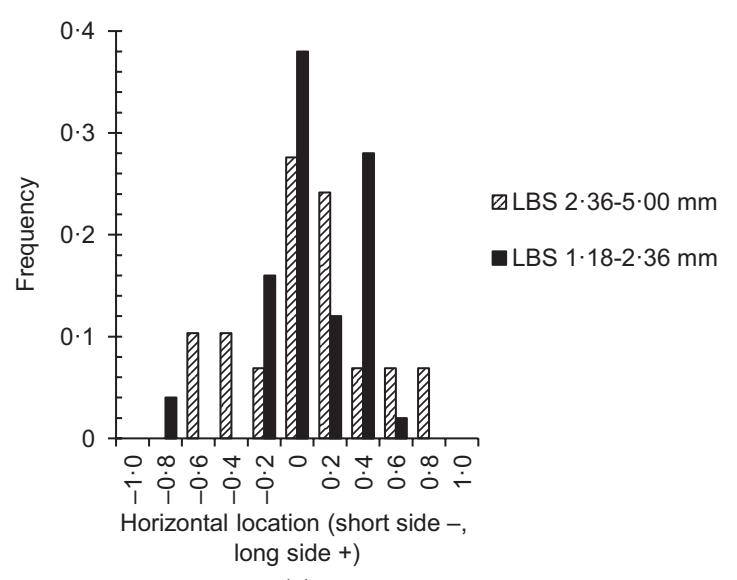

(a)

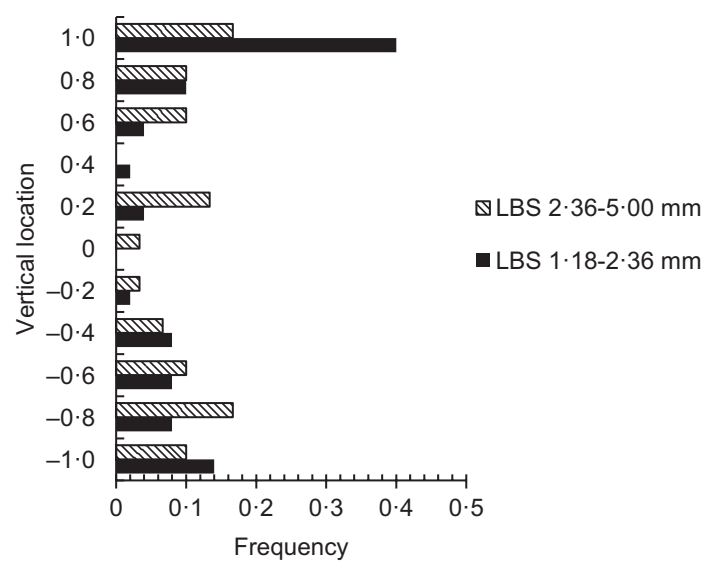

(b)

Fig. 30. Comparison of crack initiation locations for different sizes of LBS in (a) the horizontal direction and (b) the vertical direction

\section{NOTATION}

$D_{\text {cir }} \quad$ diameter of minimum circumscribed circle

$D_{\text {ins }}$ diameter of maximum inscribed circle

$d$ particle dimension $d=\left(d_{2} d_{3}\right)^{1 / 2}$

$d_{2}$ intermediate diameter of minimum section of SCC (smallest circumscribable cuboid) of particle

$d_{3}$ minimum diameter of minimum section of SCC (smallest circumscribable cuboid) of particle

$L$ longest dimension of particle

$m$ Weibull modulus

$N$ force at particle failure

$P_{\mathrm{s}} \quad$ survival probability of a particle experiencing a tensile stress $\sigma$

$R_{\text {ins }}$ radius of maximum inscribed circle of particle outline

$r_{\mathrm{c}}$ local radius of curvature at either of the contact surfaces

$r_{1}$ distance of crack initiation point from loading axis of a particle

$r_{2}$ distance of crack initiation point from central axis of a particle

$S$ shortest dimension of particle

$\sigma$ tensile stress

$\sigma_{\mathrm{f}}$ maximum tensile stress

$\sigma_{\mathrm{p}}$ peak stress

$\sigma_{0} \quad$ characteristic strength

$\rho$ regularity

$\rho_{i} \quad$ radius of curvature for contact point $i$

\section{REFERENCES}

Antonyuk, S., Tomas, J., Heinrich, S. \& Mörl, L. (2005). Breakage behaviour of spherical granulates by compression. Chem. Engng Sci. 60, No. 14, 4031-4044. 
Atkinson, B. K. (1979). A fracture mechanics study of subcritical tensile cracking of quartz in wet environments. Pure Appl. Geophys. 117, No. 5, 1011-1024.

Been, K. \& Jefferies, M. G. (1985). A state parameter for sands. Géotechnique 35, No. 2, 99-112, http://dx.doi.org/10.1680/geot. 1985.35.2.99.

Blott, S. J. \& Pye, K. (2008). Particle shape: a review and new methods of characterization and classification. Sedimentology 55, No. 1, 31-63.

Bobei, D., Lo, S. R., Wanatowski, D., Gnanendran, C. T. \& Rahman, M. (2009). A modified state parameter for characterizing static liquefaction of sand with fines. Can. Geotech. J. 46, No. 3, 281-295.

Bolton, M. D. (1986). The strength and dilatancy of sands. Géotechnique 36, No. 1, 65-78, http://dx.doi.org/10.1680/geot. 1986.36.1.65.

Brzesowsky, R. H., Spiers, C. J., Peach, C. J. \& Hangx, S. J. T. (2011). Failure behavior of single sand grains: theory versus experiment. J. Geophys. Res. 116, No. B6, B06205.

Cavarretta, I. \& O'Sullivan, C. (2012). The mechanics of rigid irregular particles subject to uniaxial compression. Géotechnique 62, No. 8, 681-692, http://dx.doi.org/10.1680/ geot.10.P.102.

Cavarretta, I., Coop, M. R. \& O'Sullivan, C. (2010). The influence of particle characteristics on the behaviour of coarse grained soils. Géotechnique 60, No. 6, 413-423, http://dx.doi.org/ 10.1680/geot.2010.60.6.413.

Cho, G. C., Dodds, J. \& Santamarina, J. C. (2006). Particle shape effects on packing density stiffness and strength: natural and crushed sands. J. Geotech. Geoenviron. Engng, ASCE 132, No. 5, 591-602.

Coop, M. R. \& Lee, I. K. (1993). The behaviour of granular soils at elevated stresses. In Predictive soil mechanics. Proceedings of the Worth memorial symposium (eds G. T. Houlsby and A. N. Schofield), pp. 186-198. London, UK: Thomas Telford.

Coop, M. R. \& Lee, I. K. (1995). The influence of pore water on the mechanics of granular soils. Proceedings of the XIth European regional conference on SMFE, Copenhagen, Denmark, vol. 1, pp. 63-73.

Gallagher, J. J. (1987). Fractography of sand grains broken by uniaxial compression. In Clastic particles: scanning electron microscopy and shape analysis of sedimentary and volcanic clasts (ed. J. R. Marshall), pp. 189-228. New York, NY, USA: Van Nostrand Reinhold.

Hardin, B. O. (1985). Crushing of soil particles. J. Geotech. Engng 111, No. 10, 1177-1192.

Hiramatsu, Y. \& Oka, Y. (1966). Determination of tensile strength of rock by compression test of an irregular test piece. Int. J. Rock Mech. Min. Sci. 3, No. 2, 89-99.

Jaeger, J. C. (1967). Failure of rocks under tensile conditions. Int. J. Rock Mech. Min. Sci. 4, 219-227.

Krumbein, W. C. \& Sloss, L. L. (1963). Stratigraphy and sedimentation. San Francisco, CA, USA: W. H. Freeman and Company.

Lee, D. M. (1992). The angle of friction of granular fills. $\mathrm{PhD}$ thesis, Engineering Department, University of Cambridge, Cambridge, UK.

Lee, I. K. \& Coop, M. R. (1995). The intrinsic behaviour of decomposed granite soil. Géotechnique 45, No. 1, 117-130, http://dx.doi.org/10.1680/geot.1995.45.1.117.

Liu, H. Y., Kou, S. Q. \& Lindqvist, P. A. (2005). Numerical studies on the inter-particle breakage of a confined particle assembly in rock crushing. Mech. Mater. 37, No. 9, 935-954.
McDowell, G. R. \& Bolton, M. D. (1998). On the micro mechanics of crushable aggregates. Géotechnique 48, No. 5, 667-679, http://dx.doi.org/10.1680/geot.1998.48.5.667.

Michalkse, T. A. \& Freiman, S. W. (1982). A molecular interpretation of stress corrosion in silica. Nature 295, No. 5849, $511-512$.

Nakata, Y., Hyde, A. F. L., Hyodo, M. \& Murata, H. (1999). A probabilistic approach to sand particle crushing in the triaxial test. Géotechnique 49, No. 5, 567-583, http://dx.doi.org/10.1680/ geot.1999.49.5.567.

Nakata, Y., Kato, Y., Hyodo, M., Hyde, A. F. L. \& Murata, H. (2001a). One-dimensional compression behaviour of uniformly graded sand related to single particle crushing strength. Soils Found. 41, No. 2, 39-51.

Nakata, Y., Hyodo, M., Hyde, A. F. L., Kato, Y. \& Murata, H. (2001b). Microscopic particle crushing of sand subjected to high pressure one-dimensional compression. Soils Found. 41, No. 1, 69-82.

Oldecop, L. A. \& Alonso, E. E. (2001). A model for rockfill compressibility. Géotechnique 51, No. 2, 127-139, http://dx.doi. org/10.1680/geot.2001.51.2.127.

Oldecop, L. A. \& Alonso, E. E. (2003). Suction effects on rockfill compressibility. Géotechnique 53, No. 2, 289-292, http://dx.doi. org/10.1680/geot.2003.53.2.289.

Ovalle, C., Dano, C., Hicher, P. Y. \& Cisternas, M. (2015). Experimental framework for evaluating the mechanical behavior of dry and wet crushable granular materials based on the particle breakage ratio. Can. Geotech. J. 52, No. 5, $587-598$.

Rocchi, I. (2014). An experimental investigation of the influence of weathering on saprolitic soils from Hong Kong. PhD thesis, City University of Hong Kong, Hong Kong.

Rocchi, I. \& Coop, M. R. (2015). The effects of weathering on the physical and mechanical properties of a granitic saprolite. Géotechnique 65, No. 6, 482-493, http://dx.doi.org/10.1680/ geot.14.P.177.

Russell, A. R. \& Muir Wood, D. (2009). Point load tests and strength measurements for brittle spheres. Int. J. Rock Mech. Min. Sci. 46, No. 2, 272-280.

Tapias, M., Alonso, E. E. \& Gili, J. A. (2015). A particle model for rockfill behaviour. Géotechnique 65, No. 12, 1-20, http://dx.doi. org/10.1680/jgeot.14.P.170.

Tsoungui, O., Vallet, D. \& Charmet, J. C. (1999). Numerical model of crushing of grains inside two-dimensional granular materials. Powder Technol. 105, No. 1-3, 190-198.

Verdugo, R. \& Ishihara, K. (1996). The steady state of sandy soils. Soils Found. 36, No. 2, 81-91.

Wadell, H. (1932). Volume, shape, and roundness of rock particles. J. Geol. 40, No. 5, 443-451.

Wadell, H. (1933). Sphericity and roundness of rock particle. J. Geol. 41, No. 3, 310-330.

Wadell, H. (1935). Volume, shape, and roundness of quartz particles. J. Geol. 43, No. 3, 250-280.

Weibull, W. (1951). A statistical distribution function of wide applicability. J. Appl. Mech. 18, 293-297.

Zhao, B., Wang, J. \& Coop, M. R. (2015). An investigation of single sand particle fracture using X-ray micro-tomography. Géotechnique 65, No. 8, 625-641, http://dx.doi.org/10.1680/ geot.4.P.157.

Zheng, J. \& Hryciw, R. D. (2015). Traditional soil particle sphericity, roundness and surface roughness by computational geometry. Géotechnique 65, No. 6, 494-506, http://dx.doi.org/10.1680/ geot.14.P.192. 